Atıf: Gürgen, G. (2019). Çatakkaya Döküntü Örtülü Buzulu (Tatos Dağları), Coğrafi Bilimler Dergisi/ Turkish Journal of Geographical Sciences, 17(1), 217-236, doi: 10.33688/aucbd.536616

Coğrafi Bilimler Dergisi

Turkish Journal of Geographical Sciences

e-ISSN:1308-9765

\title{
Çatakkaya Döküntü Örtülü Buzulu (Tatos Dağları)
}

\section{Çatakkaya debris-covered glacier (Tatos Mountains-Turkey)}

\section{Gürcan Gürgen *a}

\begin{tabular}{l} 
Makale Bilgisi \\
\hline DOI: \\
10.33688/aucbd.536616 \\
\hline Makale Geçmişi: \\
Geliş: 06.03.2019 \\
Kabul: 17.04.2019 \\
\hline Anahtar Kelimeler: \\
Glasyal Morfoloji \\
Buzullaşma \\
Döküntü Örtülü Buzullar \\
Tatos Dağları \\
\end{tabular}

\begin{tabular}{l} 
Article Info \\
\hline DOI: \\
10.33688/aucbd.536616 \\
\hline Article History: \\
Received: 06.03.2019 \\
Accepted: 17.04.2019 \\
\hline Keywords: \\
Glacial Morphology \\
Glaciations \\
Debris-Covered Glaciers \\
Tatos Mountains-Turkey
\end{tabular}

\section{$\ddot{O} z$}

Kuzey Anadolu Dağları'nın doğu kesimi, Pleistosen buzullaşmasının en etkili olduğu yerlerdendir. 3500 metreyi aşan çok sayıdaki zirveye sahip olan bu dağların, özellikle 2500 metrelerden yüksek kisımlarl kayda değer bir buzullaşma alanı oluşturmaktadır. Doğu Karadeniz Dă̆ları'nın yüksek dorukları; Kaçkar, Verçenik, Tatos (Dilek), Bulut-Altıparmak ve Göller (Hunut) dă̆larında, özellikle kuzeye bakan yamaçlarda bulunan buzullar ve buzul topografyası sahip olduklarl niteliklere bağll olarak pek çok araştırmaya konu olmuş ve olmaya da devam etmektedir. Kuzey Anadolu Dağları'nın bu yüksek doruklarının güneye bakan yamaçlarında da dikkat çekici bir buzullaşma etkisi, buzul topografyası, hatta aktüel sirk buzulları gözlenmektedir. Doğu Karadeniz Dağları’nın yüksek zirvelerinden birini oluşturan Tatos Dă̆ı'nın (3550) güney kesimi, önemli bir buzullaşmanın meydana geldiği yerler arasındadır. Pleistosen'de etkili olan buzullaşmanın izlerini yansitan tekne vadiler, buzul gölleri ve çeşitli buzul şekilleri ile birlikte bu alanda kuzeye bakan, dik yamaçlı bir glasyal sirk içinde belirlenen ve tamamen bir enkaz örtüsüyle kaplı olan Çatakkaya döküntü örtülü buzulu, bu alandaki buzullaşmanın etki ve önemini ortaya koyan kayda değer bir bulgu oluşturmaktadir.
Abstract
The eastern part of the North Anatolian Mountains is the place where the Pleistocene glaciations is most effective.In these mountains, which have many summits over 3500 meters, especially the high parts above 2500 meters constitute a significant glacial area. Important peaks of the Eastern Black Sea Mountains; Glaciers and glacier shapes on the northern slopes of Kaçkar, Verçenik, Tatos (Dilek), Göller(Hunut) and Bulut-Altiparmak have been subject to various investigations because of these features. In the Eastern Black Sea Mountains, there are also some glacial traces, glacial shapes, and even current cirque glaciers in the southern-facing parts of these summits. The southern part of the Tatos Mountains, which forms one of the highest peaks of the Eastern Black Sea Mountains, is also where glaciation is effective.The glacier valleys reflecting the traces of the Pleistocene glaciations, the various glacial shapes and glacier lakes together with the northward-facing Çatakkaya debris covered glacier, covered entirely with a rubble, detected at the steep slope of a glacial cirque is a significant finding that reveals the impact and significance of glaciation in this area.

\footnotetext{
*Sorumlu Yazar/Corresponding Author: ggurgen@ankara.edu.tr

a Ankara Üniversitesi, Eğitim Bilimleri Fakültesi, İlköğretim Bölümü, http://orcid.org/0000-0003-0224-1644
} 


\section{Giriş}

Türkiye'nin yüksek dağlık bölgeleri, Pleistosen'deki iklim koşullarına bağlı olarak önemli oranda buzullaşmaya uğramıştır. Ağrı, Süphan ve Erciyes gibi iç bölgelerin yüksek volkanik dağları, güneyde Toros Dağları'nın Bolkar ve Aladağlar zirveleri ile Güneydoğu Toroslar, kuzeyde ise Doğu Karadeniz Dağları'nın yüksek kesimleri büyük oranda buzullarla kaplanmıştır. Kuzey Anadolu Dağları'nın doğu kesimindeki, en yüksek zirveleri olan Kaçkar ve Verçenik (Üçdoruk) dağları buzullaşmanın en kuvvetli olduğu yerlerin başında gelmektedir. Bu yörede, ana hatları ile buzullaşma öncesine ait fluviyal vadilere yerleşen buzullar, derin tekne vadiler oluşturmuş, özellikle kuzey yamaçlarda uzunlukları 10 km'yi aşarken, buzul dilleri de yer yer 2000m'lerin altına inmiştir (Doğu, vd.,1993-1996). Doğu Karadeniz Dağları'nda yer tutan buzullar, ortalama 17.000 y1l öncesine tarihlenen ve mutlak yaş tayinleriyle belirlenen son glasyal evreyi takiben başlayan isınma süreçlerine bağlı olarak erimeye ve çekilmeye başlamıştır (Akçar vd., 2007, Akçar vd. 2008, Reber vd. 2014). Değişen iklim koşulları ve düşen sıcaklık nedeniyle, buzullarda bazı ilerleme dönemleri belirlenmiş olsa da (Sarıkaya ve Çiner, 2015), yakın zamanlara geldiğimizde büyük oranda erimiş ve geride önemli bir glasyal topografya bırakarak yok olmaya yüz tutmuşlardır. Bölgede, bakı ve yükseltinin etkisiyle varlığını sürdürebilen az sayıdaki buzul ise genellikle korunaklı sirk bölümlerine kadar çekilmiş ve, küçük yamaç ve sirk buzulları biçiminde korunmuşlardır (Doğu vd.,1993; Gürgen ve Yeşilyurt 2012). Türkiye'de dikkat çeken üç buzullaşma alanından biri olarak, görkemli bir glasyal topografyaya sahip olan Doğu Karadeniz Dağları'nın yüksek zirveleri ve civarı, az sayıda güncel buzulun varlığını koruduğu alanlardan biri olarak önemini korumaktadır.

Kuzey Anadolu Dağları'nın doğu kısmında, özellikle Kaçkar zirvesi civarında yaygın olmakla birlikte, Verçenik Dağı, Karçal Dağları, Altıparmak Dağları, Karadağ (Gümüşhane) ve Tatos (Dilek) Dağları'nda, güncel buzulların varlığı belirlenmiştir (Doğu vd., 1998; Gürgen, 2001, 2014, 2015; Gürgen ve Yeşilyurt, 2012). Bu zirveler ana hatlarıyla batı-doğu yönünde uzanmakta, daha sonra da kuzeydoğuya doğru, yüksek bir yay çizmektedir. Kuzey Anadolu Dağları'nın yüksek zirveleri, Kaçkar ve Verçenik arasında yer alan Tatos Dağı, Rize ile Erzurum il sınırlarının geçtiği hat üzerinde bulunmaktadır (Şekil 1). Ana hatlarıyla güneybatıdan, kuzeydoğuya doğru uzanan Tatos kütlesinin en yüksek kesimleri, dağlık alanın batı ve doğu kısımlarında yer almaktadır. Batı kesimdeki zirve $3550 \mathrm{~m}$, doğu kesimindeki zirve ise (haritalarda belirtilmemekle birlikte) 3590 m'yi aşmaktadır. Tatos Dağları üzerinde, kuzey ve güney bölümler arasında (Rize-Erzurum) günümüzde artık giderek daha az kullanılan bazı geçitler bulunmaktadır. Kütlenin batı kesiminde; 3200 m’lerden aşılan Tatos Gediği, doğu kesiminde ise Çiçekli Aşıtı (3250) dağlık kütle üzerindeki önemli geçitlerdir. Tatos Gediği civarında kuzeye yamaçta belirlenen buzul (Gürgen; 2015) dışında, kütlenin güney aklanında bulunan Çinaçor buzulundan (Gürgen 2016; Krenek 1932, Luteld 1934, 1935) sonra kütlenin doğu kısmında, Çiçekli Aşıtı yakınlarında belirlenen (Foto 1) döküntü örtülü buzul, (DÖP) oluşum koşulları ve özelliklerinin belirlenmesi bu çalışmanın en önemli amacını oluşturmaktadır. 


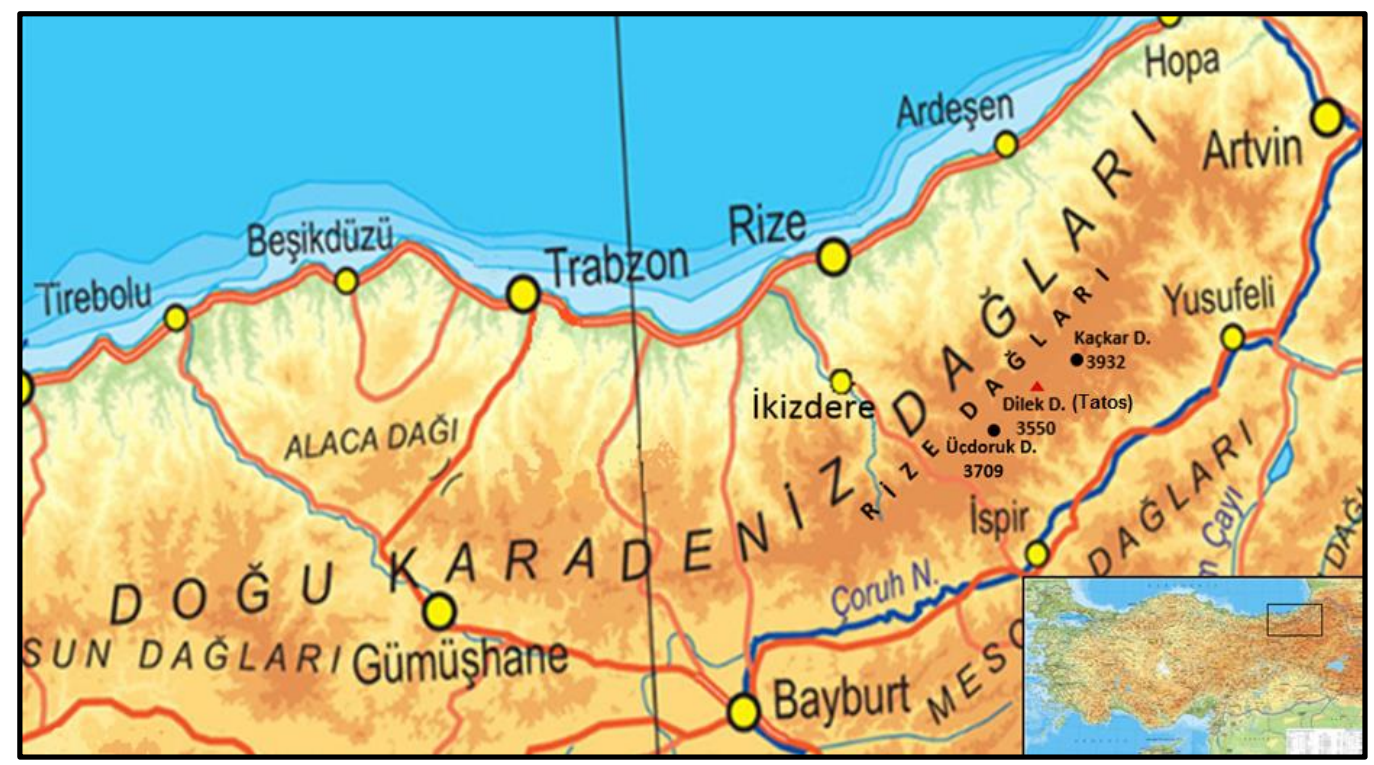

Şekil 1. Tatos (Dilek) Dağı ve çevresinin lokasyon haritası

\section{Materyal ve Yöntem}

Bu çalışma, Kuzey Anadolu Dağları'nın doğu kesiminde daha önceki araştırmalarda belirlenen güncel buzullardan sonra, yeni saptanan döküntü örtülü bir buzulun, oluşum koşulları, hâlihazırdaki durumu ve özelliklerini belirlemek için, araştırma alanında konaklamalı kamp kurularak yapılan arazi çalışma ve gözlemlerine dayanmaktadır. Saha araştırmasında önceden değerlendirilen uydu görüntüleri ve 1/25.000 ölçekli topografya haritalarından yararlanılmış, yapılan gözlemler sonucunda çeşitli veriler sağlanmıştır. Sağlanan veriler ve gözlem sonuçlarına göre çeşitli çizimler yapılmış, yeni belirlenen buzul alanının jeomorfolojik ve topografik özellikleri saptanmış, yeni bulgu ve kanıtlar ile bölge geneli ve Tatos Dağları ile yakın çevresindeki buzullaşma alanlarına ve güncel buzullar hakkında çeşitli öneriler geliştirilmiştir. Bu kapsamda, Tatos Dağları ve yörede gerçekleştirilen önceki araştırmalar da değerlendirilerek, önceki çalışmalarda bu tür bulgulara yer verilmemesinin nedenleri irdelenmiştir.

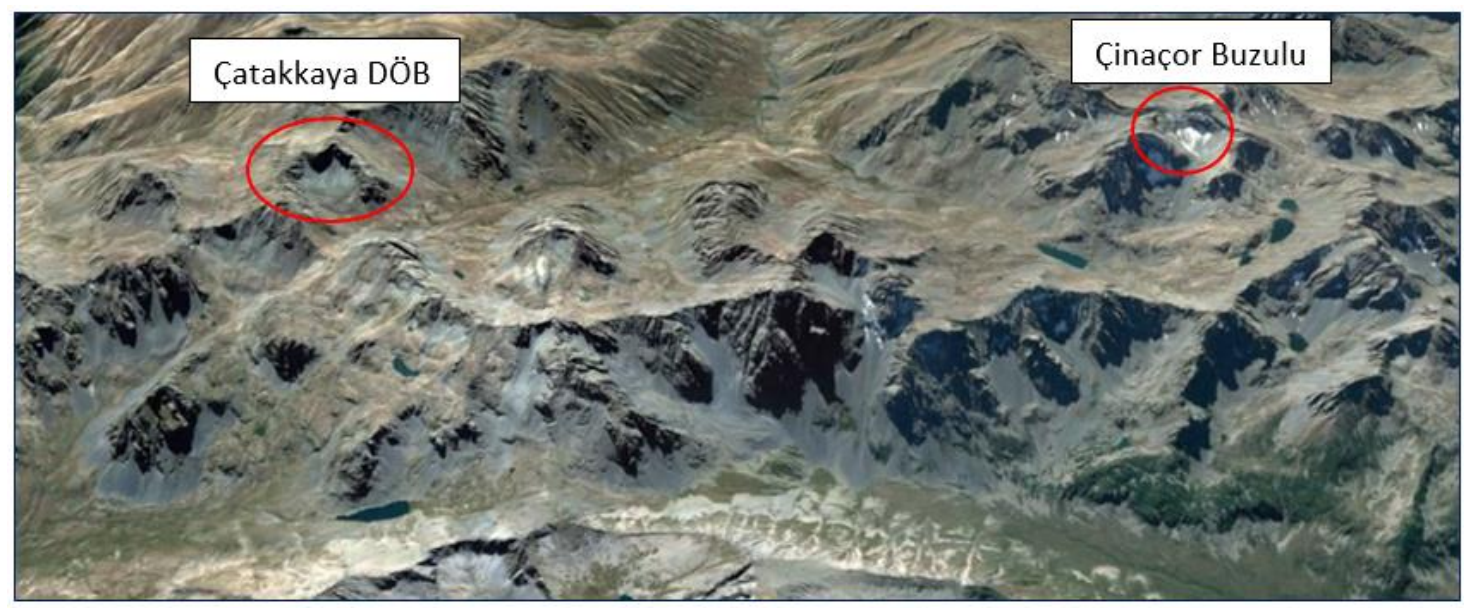

Foto 1. Tatos Dağları üzerinde bulunan Çatakkaya ve Çinaçor buzullarının Google Earth görüntüsü üzerinden belirlenen konumları ( kuzeyden bakış) 


\section{Bulgular}

Doğu Karadeniz Dağları'nın en yüksek zirveleri, aynı zamanda, bölgedeki buzul morfolojisi araştırmalarının da en yoğun olduğu yerlerdir. Dağlık kuşağın en yüksek doruğu olan Kaçkar Dağı, (3932 m.) en fazla araştırılan ve doğal olarak çok sayıda yayına konu olan bir alandır. Bu dağlık kuşağın yüksek kesimleri ve çevresinde gerçekleştirilen çeşitli araştırmalarda bir yandan yörenin buzullaşma koşulları ve buzul şekillerine değinilirken, diğer yandan da güncel ve paleoklimatolojik koşulları ele alınmıştır. Bölgede yapılan önceki çalışmalarda, dikkat çeken en önemli bulgulardan birine, Krenek, 1932 yılında ulaşmıştır. Krenek, arazideki gözlemleri sonucunda bazı krokiler çizerek, bu çizimlerin birinde isim vermemekle birlikte Tatos kütlesinin ve ana su bölümünün güneyinde bulunan, Çinaçor buzuluna yer vermiştir. Lutelt, 1934 ve 1935 yıllarında yayınlanan çalışmalarında Kuzey Anadolu Dağları'nın doğusundaki zirveler hattı ve çevresinde yaptığı gözlem ve araştırmalarda bu kütlenin yüksek kesimlerindeki glasyal topografyaya değinerek, bu alanda yıl boyu kar örtülerine rastlandığını, çeşitli yerlerde buzul, moren ve kaya buzulları hakkında bilgiler vermektedir. Lutelt'in çalışmasında yer verdiği ve daha sonra Loffler (1970) tarafından da atıfta bulunulan bir çiziminde, Verçenik ve Tatos dağları civarındaki buzul ve buzul şekilleri gösterilmektedir. Loffler (1970) Lutelt'in bu araştırmalarındaki bir çizimi alıntılamakta ve Kaçkar zirvesinin batısındaki kütlenin glasyal topografyası hakkında bilgiler vermektedir. Bölgedeki buzullaşma koşullarının belirlenmesi konusunda, çeşitli araştırmalar yapan S. Erinç, 1944-1952 yılları arasındaki çalışmalarıyla, bu alana çok önemli katkılar sağlamıştır. Krenek tarafinda belirlenen buzullara atıfta bulunan Erinç, belirlenen buzullardan birinin Kaçkar zirvesi civarında, öbürünün ise bu noktaya yaklaşık 25 uzaklıkta Verçenik yakınlarında yer aldığına değinmektedir. Erinç'in (1945) bölgede geniş bir alanı kapsayan yayınında, bu dağlık kütlenin kuzey kesimleriyle birlikte Verçenik Dağı güneyindeki (Yukarı Salaçor) sahalarda da gerçekleştirdiği çalışmalarında, önceki bulguları da değerlendirerek Kuzey Anadolu Dağları'ndaki glasyal topografyanın gelişimi konusunda önemli bilgiler vermektedir. Erinç'in bir diğer yayınında da (1952), Türkiye'deki glasyal topografya ve güncel buzullara değinilirken, Krenek’e dayandırılarak Verçenik kütlesi yakınlarında keşfedilen buzula (Çinaçor) yer verilmektedir. Dağlık kuşak genelindeki buzullaşma koşullarına yer veren bir diğer araştırıcı da H. Gall'dir (1966). Doğu Karadeniz Dağları'nın kuzey yamaçlarındaki glasyal topografyayı inceleyen Gall'in bulguları, geniş kapsamlı bir yayına dönüştürülmüştür. Bu yayında, yukarıda değinilen araştırmalara da geniş biçimde değinilmekte, yapılan değerlendirmelerle birlikte, yer verilen bazı çizimler ve fotoğraflar özellikle dikkat çekicidir. Bölgenin glasyal topografyası hakkında, Kaçkar ve diğer yüksek zirveleri kapsayan önemli bir araştırma da Loffler'e (1970) aittir. Loffler, geniş bir değerlendirme ile daha önce yapılan çeşitli çalışmalara değinmekte; Krenek-Erinç-Gall ve Luteld'in çalışmalarına yer vermekte, yayınındaki bir çizimde de Luteld'e kısmi atıfla, Tatos Dağları ve Verçenik civarının glasyal topografyası hakkında önemli bilgiler vermektedir. Loffler'in değindiği bilgiler arasında, araştırma alanı güncel buzullarla birlikte (Çinaçor ve Verçenik buzulları), yakınlarındaki farklı moren oluşumları, kaya buzulları ve buzul gölleri dikkat çekmektedir. Bölgedeki glasyal topografyayı ele alan çalışmalardan biri de A. Kurter tarafından (1991) yayınlanmıştır. Afrika'dan, Ortadoğu'ya geniş bir alandaki buzulların, literatür bulgularına yer verilerek ele alındığı çalışmanın, Doğu Karadeniz Dağları'nı içeren kısmında yöredeki güncel buzullara değinilmektedir. 
Doğu vd. (1996), ağırlıklı olarak Verçenik Dağı ve kısmen Tatos Dağı'nın kuzey yamaçlarında gerçekleştirilen çalışmalarında, buzullaşma koşulları ve buzul şekilleri hakkında bilgiler vermektedir. Daha yakın zamanlarda yapılan bir diğer çalışma, Türkiye genelindeki güncel buzul varlığını konu almakta, Doğu Karadeniz Dağları'nda o zamana kadar belirlenmiş olan buzullara değinilmektedir (Çiner, 2003). Dağlık kütlenin güney yamaçlarındaki buzullaşma koşullarının ele alındığı bir diğer çalışmada (Gürgen, 2006), Verçenik Dağı güneyinde, araştırma alanının batısında kalan alanın glasyal topografyası incelenmiştir. 2015 yılında gerçekleştirilen bir başka araştırmada ise Verçenik'in kuzey yamaçlarında bulunan ve bazıları yeni belirlenen güncel buzul varlığı ele alınmaktadır (Gürgen, 2015)

Yukarıda, Doğu Karadeniz Dağları ve araştırma alanı civarını kapsayan belli başlı araştırmalara değinilmiştir. Ağırlıklı olarak kuzey yamaçlarda yoğunlaşan çalışmalarda Doğu Karadeniz Dağları'nın yüksek zirvelerinde gerçekleşen buzullaşma ve ortaya çıkan buzul topografyası ele alınmıştır. Bakı etkisiyle buzullaşmanın daha sınırlı kaldığı güney yamaçlardaki araştırmalar daha azdır. Ancak, dikkate değer bir buzullaşma etkisinde kaldığı bilinen güney yamaçların yüksek kesimlerindeki özel koşulların etkisiyle korunan ve günümüze kadar ulaşabilen buzulların belirlenmiş olması, özellikle küresel iklim değişikliğinin etkisiyle, buzulların eriyerek yok olmaya yüz tuttuğu dönemde büyük önem taşımaktadır. $\mathrm{Bu}$ nedenle, buzullaşma koşulları ve güncel buzulları kapsayan çeşitli araştırmalarda da değinildiği üzere; Türkiye'nin güncel buzulları tamamen ortadan yok olmadan, onları kayıt altına alacak bilimsel çalışmalara ağırlık verilmelidir (Gürgen, 2015, 2016; Sarıkaya ve Çiner, 2015).

Verçenik Dağı çevresinde son yıllarda belirlenmiş olan bazı küçük buzullar (Gürgen, 2014, 2015, 2016), bu alandaki güncel buzulların dağılışı hakkında daha ayrıntılı çalışmalar yapılması gerektiğini ortaya koymaktadır. Bilinen güncel buzullar dışında, özellikle tamamıyla veya bir bölümü döküntü malzemesiyle örtülü bulunan ya da bir buz çekirdeği barındıran kaya buzulları henüz tam olarak literatüre yansıtılamamıştır. Bu yüksek dağlı kuşak üzerindeki iklim koşulları ve hava durumunun kısıtlayıcı etkileri sebebiyle, zirve hattının yılın neredeyse tamamına yakınında kar altında bulunması, arazi çalışmalarını olumsuz etkilemektedir. Bu durum, uzun yıllar boyunca arazide gerçekleştirilen çalışma sürelerini kısaltmış, giderek küçülen buzulların, çıplak gözle belirlenmesini güçleştirmiştir. Ancak, son yıllarda yaz sıcaklıklarının yüksek seyretmesi ve bazı kışlarda kar yağışının ortalamalardan daha az olması, kar örtüsünün önceki yıllara göre daha erken erimesine yol açarak, özellikle bu tür döküntü örtülü buzulların belirlenmesini kolaylaştırmıştır.

Son buzul maksimumundan beri erimekte olan buzullardan, günümüze kadar ulaşanların boyları, doğal olarak çok kısalmış, küçülmüş ve yüksek sirkler bölümüne çekilmişlerdir. Beslenmesi azalan ve duran buzullar hareket kabiliyetini yitirdikten sonra, üzerlerine dökülen enkaz malzemesini artık taşıyamamakta, çıplak buzul buzu yavaş yavaş bir örtüyle kaplanmaktadır. Buzulların üstünü örtmeye başlayan 2-3 cm'lik ince bir döküntü malzemesi erimeyi artırırken, kalınlığı 4-5 cm'yi geçtikten sonra güçlü bir yalıtım sağlamakta, kalınlık artıkça, enkaz örtüsü altındaki buzulun kütle kaybı da azalmaktadır. Örneğin; Himalayalar'daki (Nepal) Khumbu buzulunda yapılan araştırmalarda, döküntü malzemesinin kalınlığı $10 \mathrm{~cm}$ 'ye ulaştığında, ablasyon oranının çıplak buzula göre \%40'dan fazla azaldığı belirlenmiştir. (Gürgen vd., 2010; Takeuchi vd., 2000). Bu nedenle, özellikle fiziksel ayrışmanın kuvvetli olduğu yüksek dağl1k alanlarda, hızlı gelişen bir döküntü örtüsü, bu tür buzulların 
oluşumunu sağlamakta ve çevresinde bulunan çıplak buzulların tamamen erimiş olmalarına karşın, sağladığı yalıtım ile korunmalarını sağlamaktadır.

Tatos (Dilek) Dağları'nda, su bölümünün güney kısmında, Tatos Gediği yakınlarındaki Çinaçor buzulu bu alanın batı kesiminde yer almaktadır. Çatakkaya döküntü örtülü buzulu ise Tatos Dağları güney buzullaşmasının doğu kesiminde, yükseltisi $3500 \mathrm{~m}$. ye yaklaşan yüksek sırt ve yamaçlarla çevrelenen bir sirk içinde bulunmaktadır (Şekil 2, 3). Su bölümünün güneyinde, Çoruh havzasına akış1 bulunan bu alandaki glasyal topografya, dağın yüksek kısımlarına yerleşen çok sayıdaki sirkten beslenen buzulların açtığı tekne vadiler, asılı vadiler ve buzul göllerinden oluşmaktadır. Günümüzde ana hatlarıyla kuzeye bakan sirkler içinde iki güncel buzul barındıran bu sahadaki buzullaşma, iki belirgin tekne vadi oluşturmuştur. Zorni Yaylası yakınlarında birleşen buzul vadilerinin uzunluğu 6 km'yi bulmaktadır (Şekil 2).

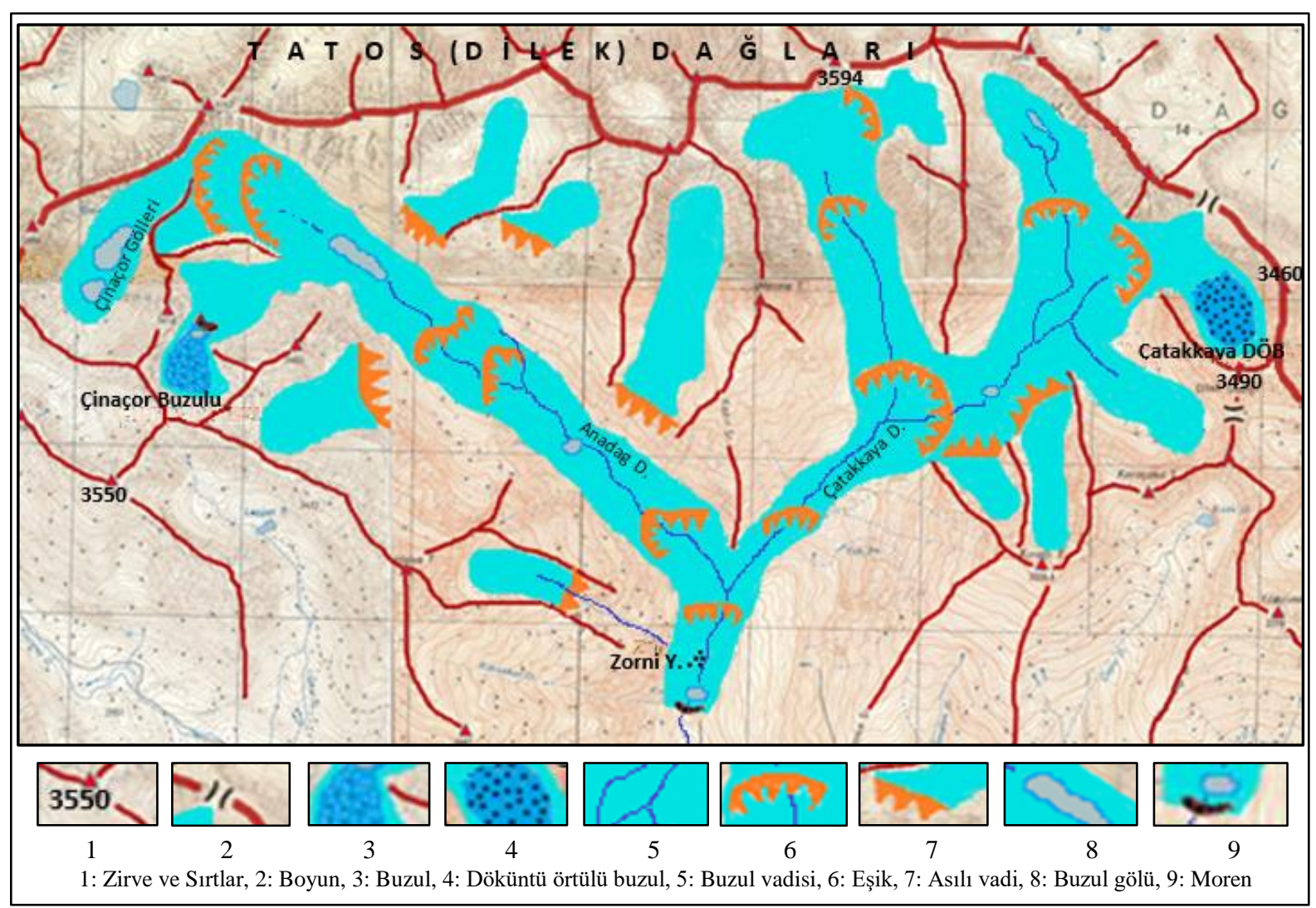

Şekil 2. Tatos Dağı güney aklanındaki buzul vadileri ile Çinaçor ve Çatakkaya buzullarının konumu.

Hemen tamamı bir döküntü örtüsü altında bulanan Çatakkaya döküntü örtülü buzulunun, toplam uzunluğu $520 \mathrm{~m}$, genişliği ise $400 \mathrm{~m}$. civarındadır. Buzulu örten enkaz malzemesi, sirkin yukarı kesimlerinde hem ince unsurlardan meydana gelmiştir, hem de kalınlığg daha azdır. Yukarıdan aşağ1 kesimlere doğru gidildikçe örtüyü oluşturan volkanik unsurlar irileşmekte, iri bloklara dönüşen örtünün görünür kalınlığı 10 metreyi aşmaktadır.

Döküntü örtülü buzulların herhangi bir kütle artışı olmasa da, üzerlerindeki enkaz malzemesinin neden olduğu basıncın etkisiyle ilerlemeye devam edebildikleri, bunun sonucunda da morfolojilerinde 
bazı değişikliklerin oluştuğu bilinmektedir (Tomphson vd., 2000). Çatakkaya döküntü örtülü buzulunda, enkaz örtüsü altındaki buzul kütlesinin yüzeye yansıyan morfolojisine bağlı olarak, üç kademe belirlenmiştir (Foto 2). Bu seviyeler, sadece yükselti ve eğim koşulları bakımından değil, örtüyü oluşturan malzemenin boyutları ve göreceli yenilik-eskilik ilişkisi bakımından da çok belirgindir.

Hemen tamamı döküntü örtüsüyle kaplı olan ve bu nedenle belirlenmesi güç olan bu tür buzullardaki bazı özellikler, bu konuda önemli ipuçları da vermektedir. Bunların en önemlilerinden biri; enkaz materyali üzerinde bir gölün bulunmasıdır. Enkaz örtüsü üzerindeki düze yakın veya az eğimli yerlerde bulunan ( $2^{\circ}$ civarında) irili ufaklı buzul üstü (Supraglacial) göller, genellikle buzul altındaki tünel ve boşlukların çökmesiyle, ya da enkaz malzemesinin oluşturduğu setlerin gerisindeki çukurlukların yă̆ış ve erimelerden kaynaklanan sularla dolmasıyla meydana gelmektedirler. Geçirimsiz bir tabaka işlevi gören buz kütlesi üzerinde tutulan sular, küçük buzul üstü gölleri oluşturmaktadır (Gürgen vd., 2010). Yaz aylarında kısa bir dönem için eriyen kar ve buz tabakalarının ortadan kalkmasından sonra çıplak gözle görülebilen bu küçük göller, Çatakkaya döküntü örtülü buzulunun belirlenmesinde de önemli bulgulardan birini oluşturmuştur.

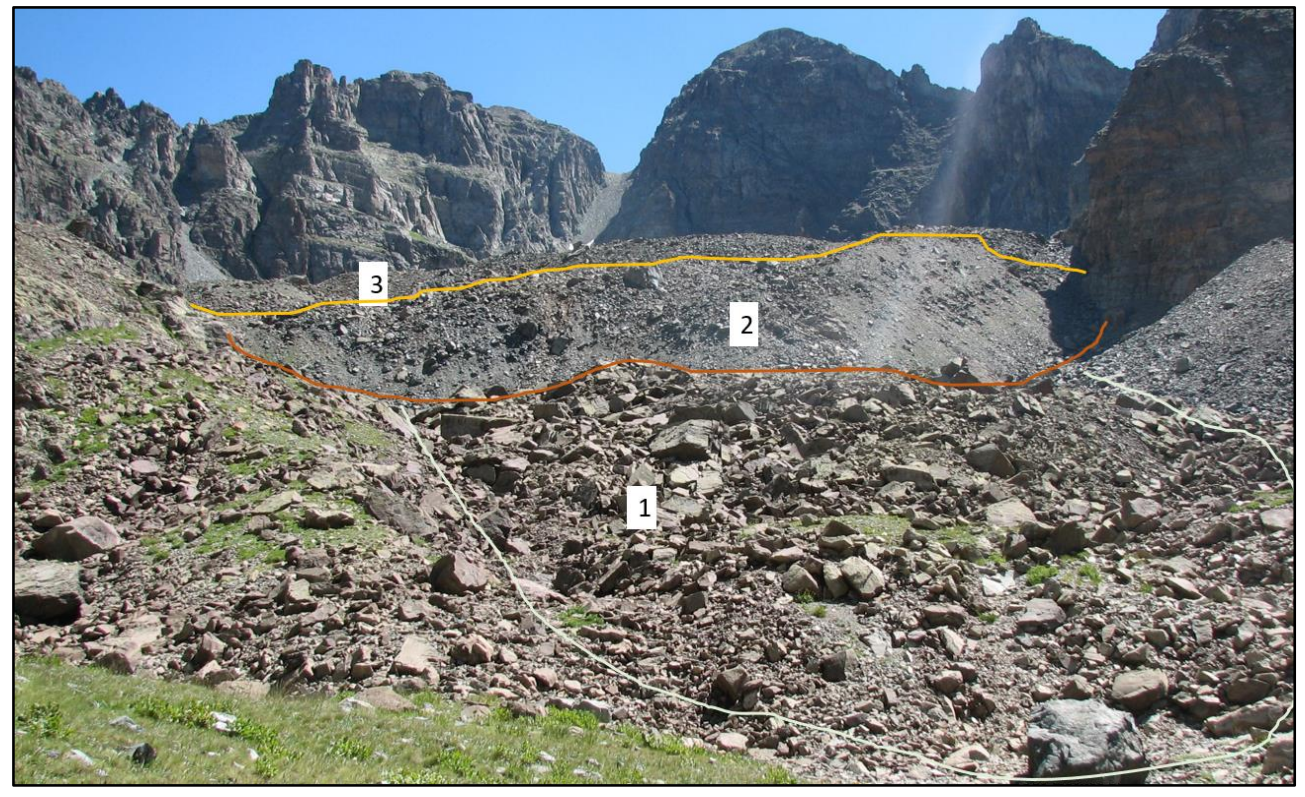

Foto 2. Çatakkaya döküntü örtülü buzulunun dil kısmından görüntüsü. Buzulu örten enkaz malzemesinin oluşturduğu üç kademe, eğim, materyal boyutu ve konumları itibarıyla net olarak birbirinden ayrılmaktadır. Bu durum buzulun hareket aşamalarını yansıtması bakımından önem taşımaktadır.

Çatakkaya döküntü örtülü buzulunun üzerinde bu koşulları yansıtan 4 küçük göl belirlenmiştir (Foto 3). Bunlar, yüzeyin en az eğimli kısmında ve enkaz malzemesinin dil kısmına yakın kesimde oluşturduğu setler arasında bulunmaktadır. Bu göllerden yukarı kesimde olanı bir çökme alanında, diğerleri ise enkaz malzemesinin oluşturduğu yığınların arasındaki çukurluklarda meydana gelmiştir. Buzulda meydana gelen çökme sonucunda oluşan göl yaklaşık $5 \times 8 \mathrm{~m}$. boyutlarında olup, bir kenarını kuşatan buz falezinin görünür yüksekliği $80-100 \mathrm{~cm}$. kadardır (Foto 4). Çakıl ya da blok boyutundaki materyalden oluşan, geçirimli bir enkaz örtüsünün, altında bir buz katmanı olmaksızın su tutamayacağı 
düşünüldüğünde, bu küçük su birikintilerinin özellikle de çıplak yüzeyleri son derece sınırlı olan döküntü örtülü buzulların belirlenmesinde ne kadar önemli olduğu açıktır.

Çatakkaya döküntü örtülü buzulunun, sirk yamacına tırmanan yüksek ve dik kesimleri dâhil, enkaz örtüsüyle kaplı durumdadır. Ancak, bu kesimdeki enkaz örtüsü ince ve küçük boyutlu unsurlardan oluştuğu için, bazı yerlerde buzul üstü akışlara bağlı olarak süpürülmüş, küçük erime kanalları meydana gelmiştir. Bununla birlikte, çıplak buzulun ortaya çıktığı bu küçük yüzey parçalarının uzaktan görülmesi ve anlaşılması pek mümkün değildir. Bu nedenle çıplak buzul buzunun görülebilmesi için, o alana iyice yaklaşılması gerekmektedir. Buzullaşma alanının, özellikle yukarı kesimlerinde, eğimin fazla olduğu yamaçlardaki enkaz örtüsünün çok ince olması nedeniyle, bazı yerlerde yüzey örtüsü $5-10 \mathrm{~cm}$. kazıldığında temiz buzul buzu ortaya çıkmakta, aşağı kesimlerde ise örtü kalınlığı arttığı için buzula ulaşmak gittikçe güçleşmektedir (Foto 5).

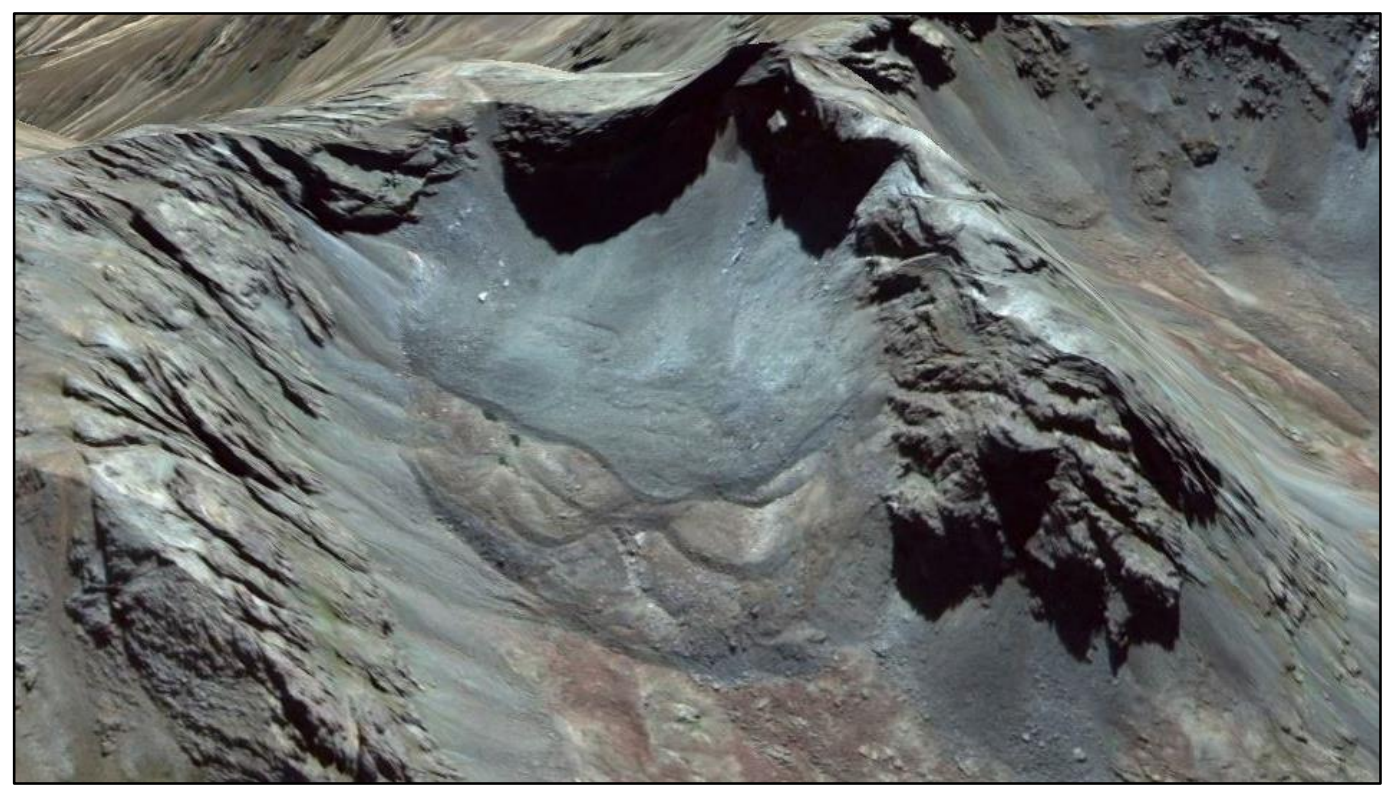

Foto 3. Çatakkaya döküntü örtülü buzulunun Google Earth görüntüsü. Buzulu örten enkaz malzemesinde buzulun hareketlerini yansıtan loblar ve küçük buzul üstü göller bu tür buzulların belirlenmesinde önemli ipuçları vermektedir. Buzulun dil kısmında yüzeyde ya da alt kesimde, erimeden kaynaklanan bir su çıkışının olmaması dikkat çekicidir. 


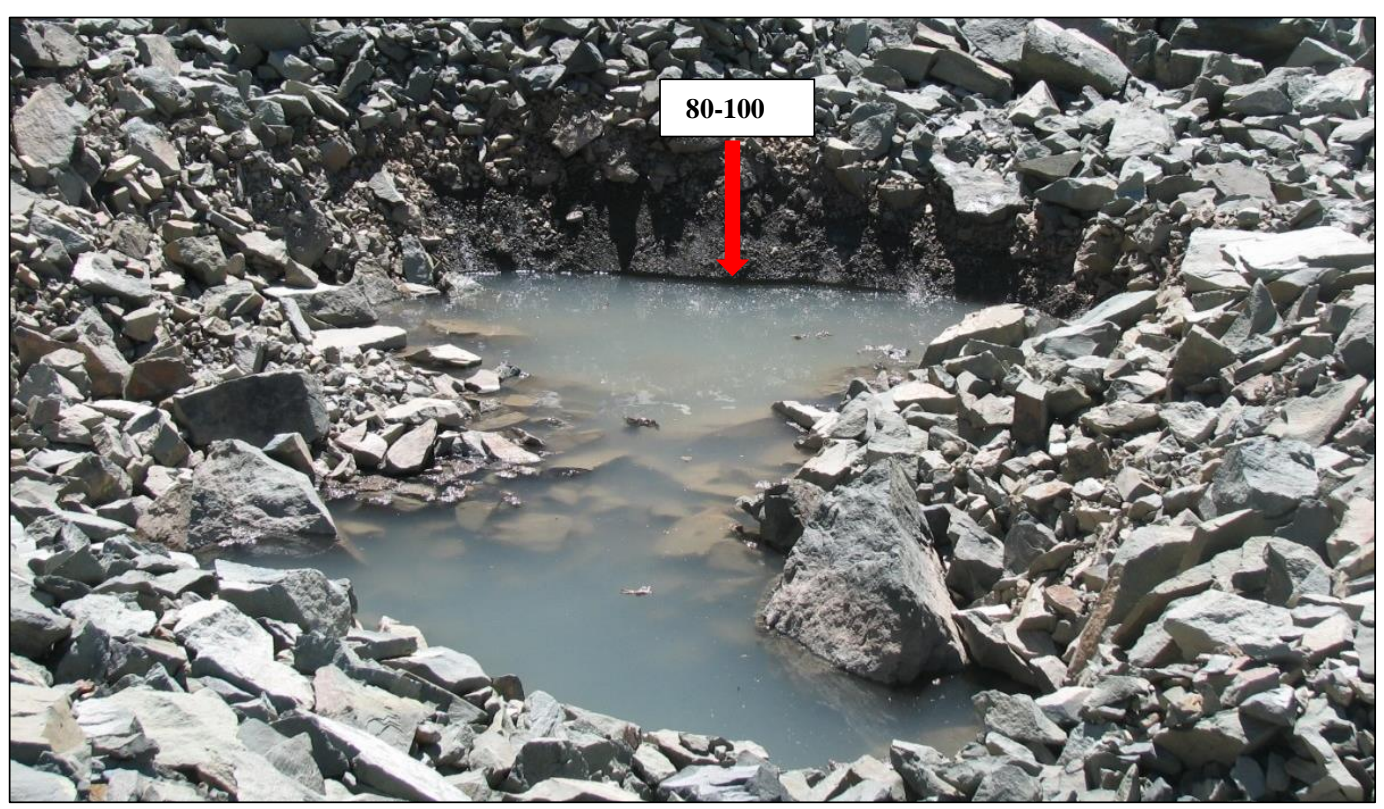

Foto 4. Çatakkaya döküntü örtülü buzulunda çökme sonucunda oluşan küçük gölün bir yamacını 80-100 cm. yüksekliğinde bir buz falezi kuşatmaktadır. Döküntü örtülü buzulun dışarıya açılan penceresi durumundaki bu küçük göller, buzuldaki ablasyonun en fazla olduğu yerleri oluşturmaktadır.
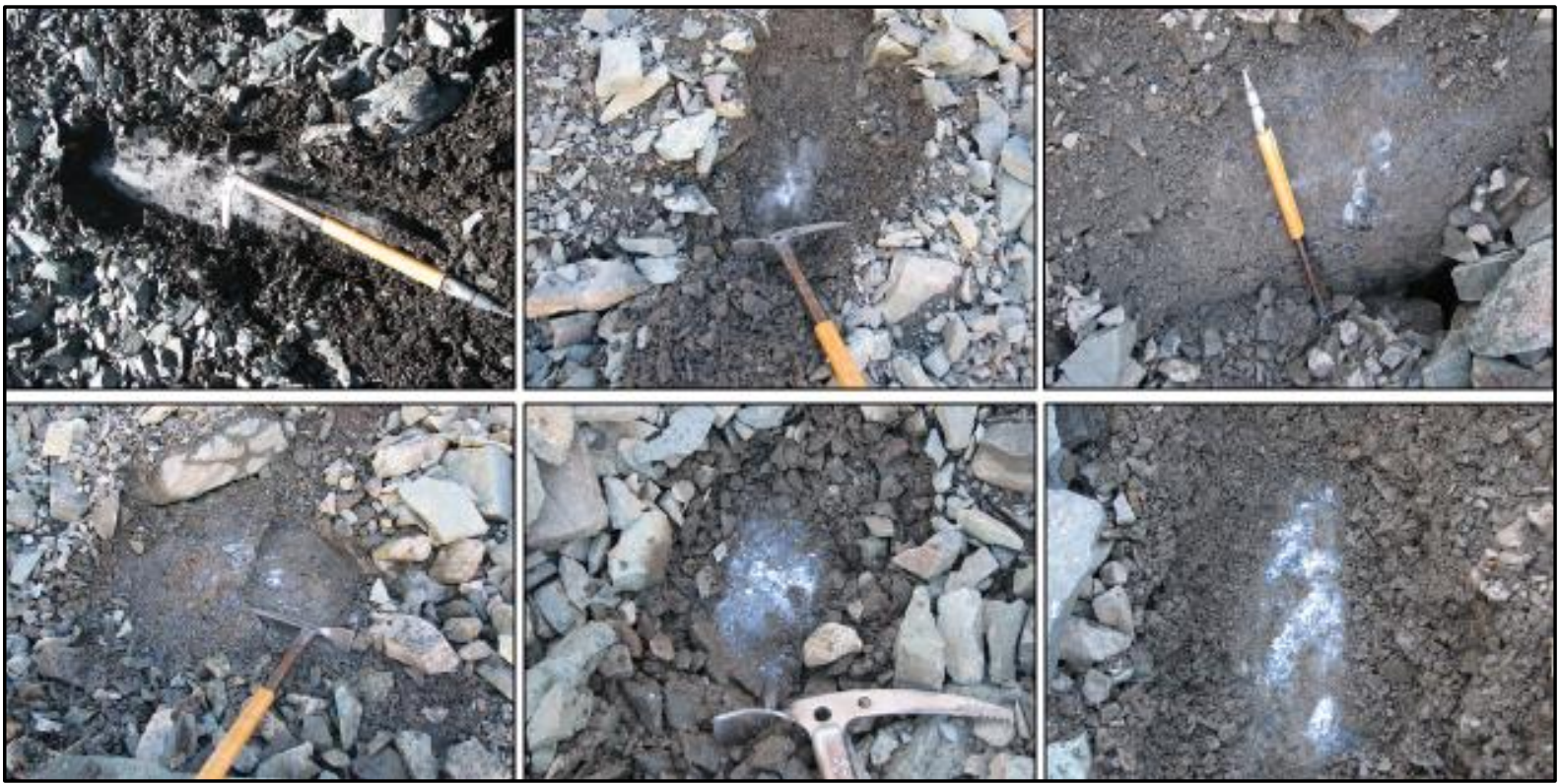

Foto 5. Çatakkaya buzulunda yüzeyin hemen tamamı enkaz malzemesiyle örtülü durumda olduğu için çıplak buzul yüzeyi neredeyse hiç görülmemektedir. Ancak, özellikle yukarı kesimlerde yüzeyi örten malzeme biraz eşildiğinde buzul açı̆̆a çıkmaktadır. Yukarı kesimlerde 5-10 cm.de ulaşılan çıplak buzul yüzeyi, aşağılara inildikçe örtü kalınlığına bağlı olarak çok daha derinlerde kalmakladır. 


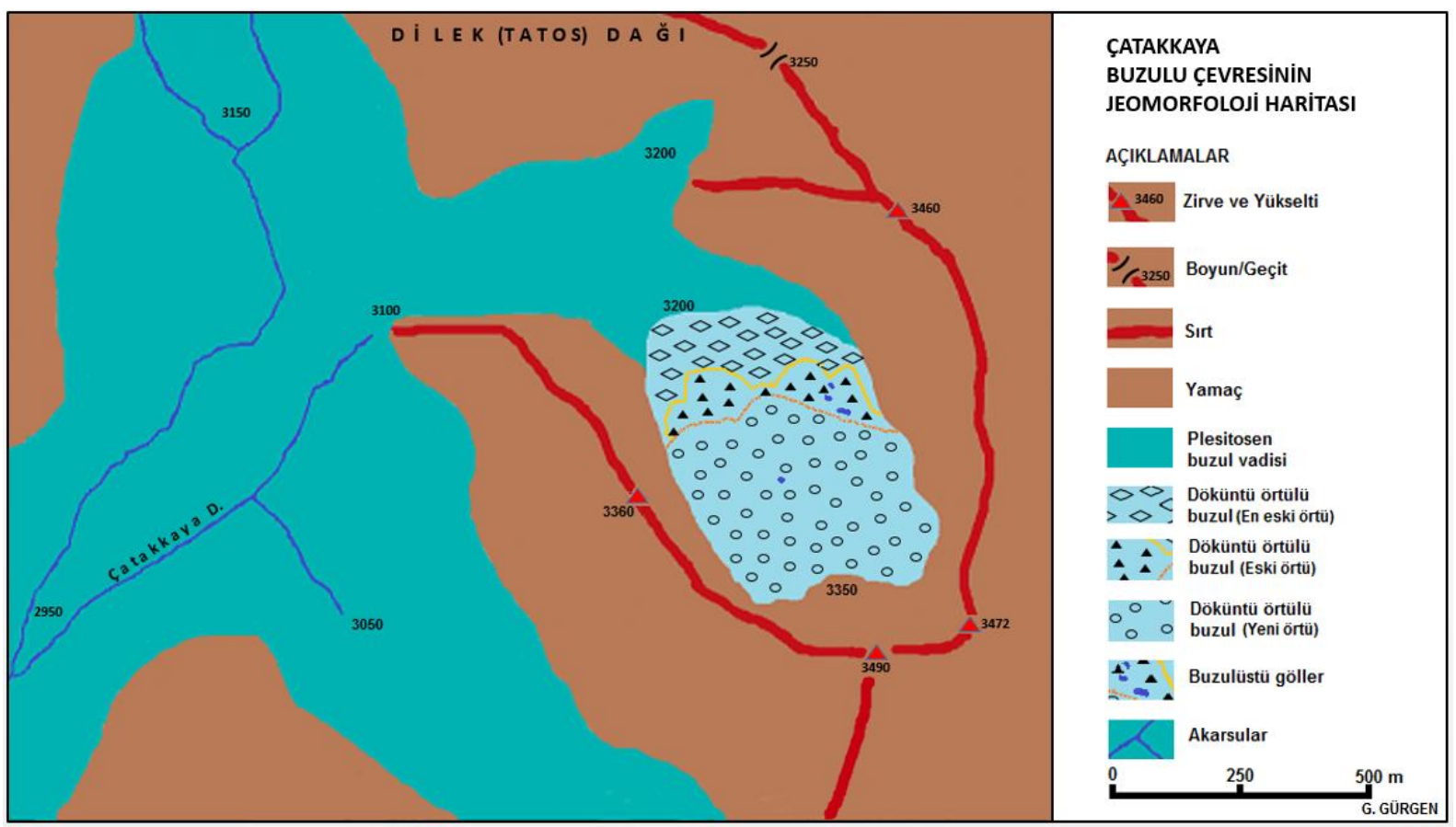

Şekil 3. Çatakkaya döküntü örtülü buzulu ve yakın çevresinin jeomorfoloji haritası.

Çatakkaya döküntü örtülü buzulunun aşağı kesimlerini kaplayan enkaz örtüsü, bu yığınlar altında kalan buzulun kütlesi ve morfolojisine bağlı olarak daha çok bir kaya buzuluna benzemektedir. Bu nedenle, çıplak buzula ait bir yüzey parçası görülmeden, bu döküntü materyalinin altında bulunan bir buzulun belirlenmesi oldukça güçtür. Bu tür güçlükler, benzer koşullar altında, yamaç ve sirklerde tutunan küçük buzul kalıntılarının çoğunda olduğu gibi, iklim koşullarının doğal etkisine bağlı olarak giderek eriyip küçülerek, korunaklı yüksek yamaçlara çekilen ve genel olarak yılın çok büyük bir kısmında benek kar örtülerinin altında kalan buzulların saptanmasını oldukça zorlaştırmaktadır.

Gürgen vd. (2010) tarafindan, döküntü örtülü buzullar ve kaya buzullarının oluşum mekanizmaları ile özelliklerine, literatürden geniş ölçüde yararlanılarak değinilmiştir. Buna göre, özellikle Alpin tip buzullaşma alanlarında normal buzulların beslenmeleri durduğunda, çevrelerindeki kayaç yapılarına da bağlı olarak hızla döküntü örtülü buzullara, daha sonra da kaya buzullarına dönüşebilmektedir. Bu durumda da ortaya çıkan şeklin döküntü örtülü buzul mu, yoksa kaya buzulu mu olduğu genellikle bir tartışma konusudur. Bu iki oluşum için, özellikle de kaya buzulları hakkında herkesin üzerinde tam olarak anlaştığı tanımlar olmamakla birlikte, belirleyici olan gene de enkaz altındaki buz kütlesidir. Döküntü örtülü buzullarda, çevresel koşullara bağlı olarak, çıplak buzul kısmen ya da tamamen bir enkaz örtüsü altındadır. Bu alanlarda, çıplak buzul yüzeyinin görülüyor olması, ya da örtünün sıyrılmasıyla kolayca açı̆̆a çıkması, eğim koşullarının uygun olduğu pek çok yerde görüldüğü üzere, buzul üstü göller barındırması döküntü örtülü buzulları kaya buzullarından ayırt eden temel özelliklerdendir. Buzulların üzerini örten enkaz malzemesi güçlü bir yalıtım sağladığından, sıcaklık artışına rağmen geri çekilmedikleri gibi bazı durumlarda ilerleme bile sağlamakta, şekillenmeye devam edebilmektedirler. Bu tür buzulların en büyük kütle kayıpları, çökmeler sonucunda oluşan buz falezleri, buzul üstü göller ve seller sonrasında, döküntü malzemesinin süpürülmesiyle açılan buzul üstü 
kanallardan olmaktadır. Döküntü örtülü buzullar son aşamalarında genellikle buz çekirdekli kaya buzullarına dönüşmektedirler. Kaya buzulları; genel olarak buz ve enkaz karışımının donma çözülme olayları ile şekillenen ya da kalın bir enkaz deposu altında buz çekirdeği barındıran glasyal şekillerdir. Permafrost etkisiyle oluşan kaya buzulu eğim koşullarına bağlı olarak şekil kazanırken, buz çekirdekli kaya buzulu, döküntü örtüsü altındaki buz kütlesinin hareketine bağlı olarak şekillenmektedir. Bu durumda kaya buzulları, bir buz çekirdeği içerseler bile yüzeyinde çıplak buzul yüzeylerinin görülmediği, kalın bir enkaz malzemesi içeren şekillerdir. Bu özellikler, döküntü örtülü buzulları, kaya buzullarından ayırt eden en belirgin farklardandır.

\section{Sonuç}

Verçenik ve Kaçkar dağları arasında bulunan Tatos (Dilek) Dağları, Doğu Karadeniz Dağları'nın nispeten az bilinen yüksek dağlık kütlelerinden biridir. Bu alanın güney yamaçlarının yüksek kısımlarında görkemli bir glasyal topografya bulunurken, yükselti ve bakı koşullarına bağlı olarak, günümüze kadar ulaşan bazı küçük güncel buzullar da varlığını sürdürmektedir. 3500m'leri aşan zirveleri ve buzul gölleriyle dikkat çeken Tatos Dağları ve çevresinde yapılan çeşitli araştırmalarda glasyal topografya ve buzullaşma koşullarıyla ilgili önemli bilgilere ulaşılmış, Doğu Karadeniz Dağları üzerinde belirlenen güncel buzullara ilk kez bu çalışmalarda yer verilmiştir. Ancak, yakın zamanlarda yapılan bazı araştırmalar, bölgede hâlâ bilinmeyen bazı küçük güncel buzulların varlığını ortaya koymaktadır. Bu çalışmalarda, yakın zamanlarda belirlenen buzullar hakkında bilgiler verilirken, yeni bulgulara bu zamana kadar neden ulaşılamadığı da tartışılmaktadır (Gürgen, 2015, 2016). Bu durumun en önemli sebebi, Tatos-Verçenik dağlarının zirve bölümlerinde, günümüz iklim ve hava şartlarına bağlı olarak, önemli oranda kar yağması ve bu alanlardaki karların neredeyse, ağustos sonlarına kadar erimemesidir. Özellikle kuzeye bakan, korunaklı sirk yamaçlarında yer yer birkaç m’yi aşan, kar örtüleri bazı yıllarda hiç erimemektedir. Ayrıca, dönemsel olarak bazı kışlarda fazla kar yağışı olması, yaz aylarının serin geçmesi, kapalı havaların çoğunlukla olması, karla örtülü geçen süreyi uzatmaktadır. Bu durum, güncel buzulların kolaylıkla belirlenebileceği ve çıplak gözle görülebileceği süreyi çok azaltmakta, bazı yıllarda da tamamen engellemektedir. Bu duruma, döküntü örtülü buzul kavramının nispeten yeni olması da eklenince, yörede yapılan önceki çalışmalarda bu tür bulgulara neden yer verilmediği anlaşılabilmektedir.

Doğu Karadeniz Dağları, Türkiye'nin önemli bir buzullaşma alanı olmakla birlikte güncel buzul varlığı sınırlıdır. Kuzey Anadolu Dağları'nda, güncel buzul varlığının yok denecek kadar az olduğu güney kısımlarında ise, mevcut güncel buzulların konumları, özellikleri ve hâlihazırdaki durumlarının belirlenmesi büyük önem taşımaktadır. Bu tür buzullar yörenin paleoklimatolojisi ve glasyal morfolojisinin evrimsel aşamalarını ortaya koyan çok önemli kanıtlardır. Bu nedenle, Çatakkaya döküntü örtülü buzulu, Doğu Karadeniz Dağları'nda bilinen az sayıdaki güncel buzul varlığına eklenen önemli bir bulgudur. Tatos Dağları'nın batı kısmındaki Çinaçor buzuluyla birlikte, bu bölgede, bir kütlenin güney aklanında bulunan iki ayrı güncel buzulun varlığı ilk kez belirlenmektedir. Değişen iklim koşulları ve artan sıcaklık değerleri nedeniyle, yok olma aşamasına gelen buzullar arasında, az sayıdaki çıplak buzulla birlikte (onların da genel olarak aşağı kesimleri döküntü örtülüdür) uygun koşullar oluştuğunda döküntü örtülü buzullara ve buz çekirdekli kaya buzullarına dönüştükleri anlaşılmaktadır. $\mathrm{Bu}$ olgu, iklime ve çevresel koşullara bağlı olarak, buzul varlığının son aşamalarında ortaya çıkan 
durumu işaret etmektedir. Son yıllarda, Kuzey Anadolu Dağları'nda yapılan çalışmalarda elde edilen veriler, bu bakış açısıyla yapılacak ayrıntılı araştırmalarda, yeni bulgulara ulaşılabileceğini ve tamamen yok olmadan önce bazı yeni küçük buzulların belirlenebileceğini ortaya koymaktadır.

\section{Notlar}

1. Çatakkaya, Erzurum'a bağlı İspir ilçesi sınırları içinde yer alan ve eski ismi "Çinaçor" olan köyün adıdır. Araştırma alanı, günümüzde mahalle statüsünde olan bu yerleşim birimi sınırları içinde yer almaktadır.

2. Bu makalenin bir bölümü Türk Coğrafya Kurumu 75.Y1l Uluslararası Kongresinde (Ankara-2017) bildiri olarak sunulmuştur. 
To cite: Gürgen, G. (2019). Çatakkaya Debris-Covered Glacier (Tatos Mountains-Turkey), Coğrafi Bilimler Dergisi/ Turkish Journal of Geographical Sciences, 17(1), 217-236, doi: 10.33688/aucbd.536616

\begin{tabular}{ccc} 
Coğrafi Bilimler Dergisi & Cografi \\
Bilimler & Dergisi \\
\hline
\end{tabular}

\section{Çatakkaya Debris-Covered Glacier (Tatos Mountains-Turkey)}

Gürcan Gürgen*a

\section{EXTENDED ABSTRACT}

\section{Introduction}

Turkey's high mountainous regions have been considerably subjected to glaciations depending on the climatic conditions in Pleistocene. The high volcanic mountains such as Ağr1, Süphan and Erciyes of the inner regions, the Bolkar and Aladağlar peaks of the Toros Mountains and the Southeastern Toros Mountains in the south, and the high sections of the Eastern Black Sea Mountains in the north are mostly covered with glaciers. Kaçkar and Verçenik (Üçdoruk) mountains (Figure 1), which are the highest peaks of the Eastern Black Sea Mountains, are one of the places where glacialisation is the strongest. In this region, the glaciers settled in the pre-glaciation fluvial valleys with their outlines, forming deep boat valleys. Especially in the northern slopes, the height and length of those glaciers exceeded 2000m and $10 \mathrm{~km}$, respectively. (Doğu et al.,1993, 1996) Glaciers of the North Anatolian Mountains began to melt due to the warming processes started about 17.000 years ago (Akçar et al., 2007, Akçar et al. 2008, Reber et al. 2014). Although some progress periods have been identified in glaciers due to changing climate conditions and falling temperatures (Sarrkaya and Çiner, 2015), they have recently melted down and faced extinction while leaving a significant glacial topography. In the region, a few glaciers which could survive under the effect of exposure and elevation generally retreated up to sheltered cirque sections and be preserved in the form of small cirque and slope glaciers (Doğu et al., 1993, Gürgen and Yeşilyurt, 2012).

Being one of the three major glaciation area in Turkey and having a magnificent glacial topography, the highest peaks and surroundings of North Anatolian Mountains maintain its importance as one of the areas where few current glacier survive. After the Çinaçor glacier present at the southern slope of the mass (Gürgen 2016; Krenek 1932; Luteld 1934, 1935), exluding the glacier discovered in the northern slopes near Tatos Breach (Gürgen, 2015), The main purpose of this research is to reveal the debris covered glacier detected near "Çiçekli Pass" and its characteristics (Photo 1).

\footnotetext{
*Corresponding Author: ggurgen@ ankara.edu.tr

a Ankara University, Department of Elemantary School Education, Ankara, Turkey, http://orcid.org/0000-0003-0224-1644
} 


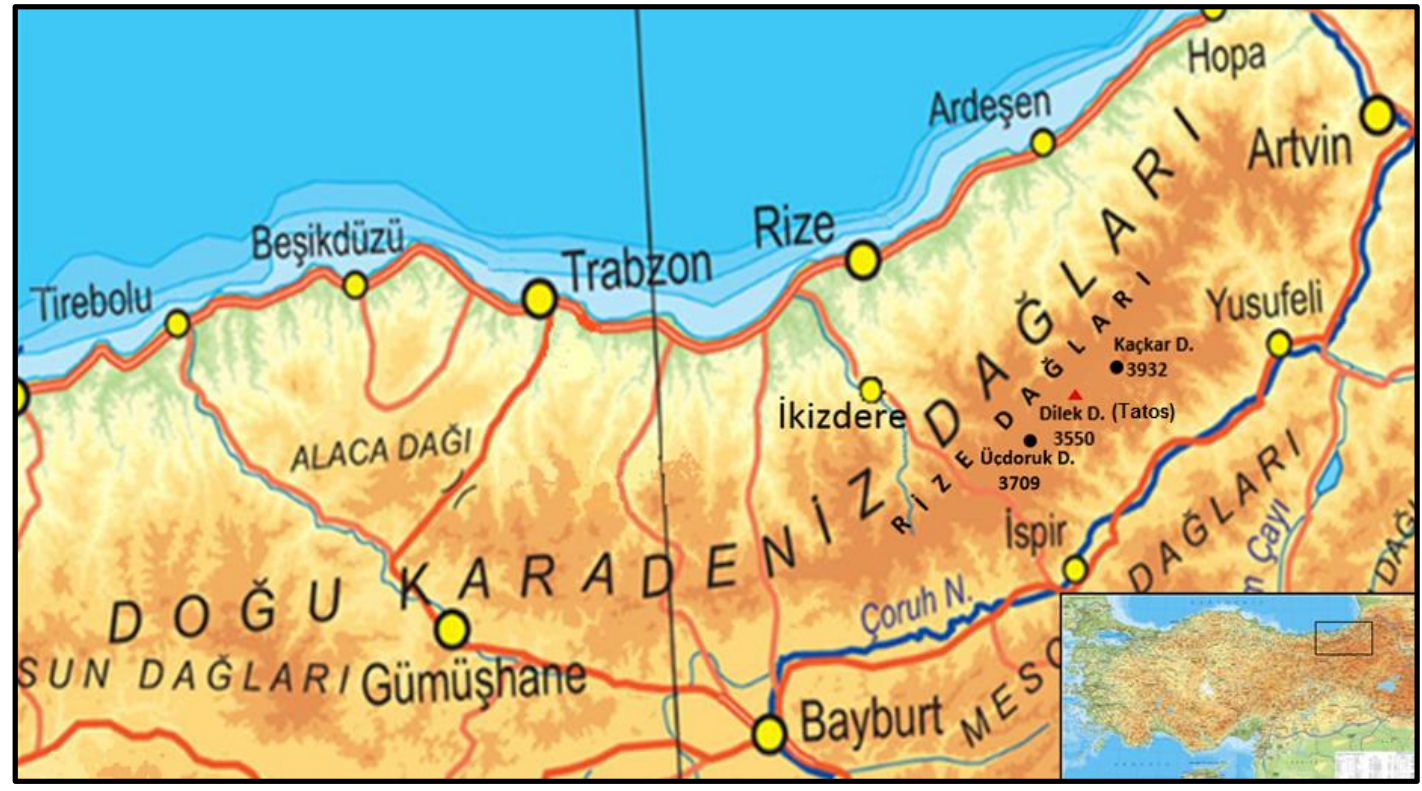

Figure 1. Location map of Tatos (Dilek) Mountain and its surroundings

\section{Methodology}

In addition to the current glaciers in the Eastern Black Sea Mountains, this research is mainly based on the field study carried out in the relevant area to reveal the status and characteristics of a newly identified debris covered glacier. In the field studies, the results obtained by using the $1 / 25000$ scale topography maps and satellite images were evaluated and the morphological and morphometric analyzes of the determined glacial area were made. Based on the results obtained, some suggestions were included regarding the glacial areas around the region and Tatos Mountains.

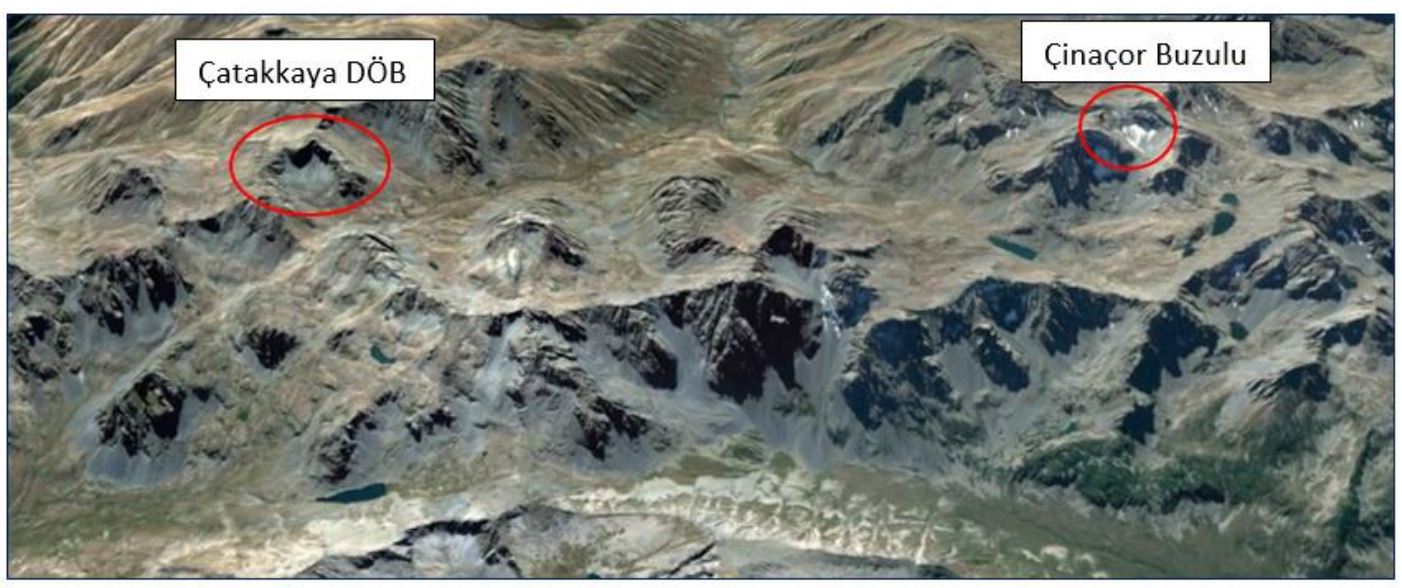

Photo 1. Location of Çatakkaya and Çinaçor glaciers on the Tatos Mountains (google earth view).

\section{Results}

Small slope and cirque glaciers, which have been identified around the Verçenik Mountain in recent years (Gürgen, 2014, 2015, 2016), revealad that this region should be further studied to identify glaciers. Except for the current glaciers, there is no studyon especially rock glaciers, which were 
partially or completely covered by a debris or including an ice core, in the literature. On this high mountain belt, the fact that the summit line remaining under snow for almost all year long due to the climatic factors and the restriction of weather conditions, negatively affects field work. This situation has shortened the working hours in the field for many years and it has made it difficult to determine the diminishing glaciers by the naked eye.However, the high summer temperatures in the recent years and the fact that snowfall in some winters has been lower than the averages have led to the earlier melting of the snow cover, which facilitated the identification of covered glaciers in particular.Glaciers have been melting since the last glacial maximum. The height of glaciers that reached to the present day have naturally shorthened and shrunk, withdrawed to high cirque section.After its supply decreased and finally stopped, glaciers experienced movement loss and no longer carry the debris material, glacial ice slowly started to be covered with a coating.A $2-3 \mathrm{~cm}$ thin debris material that starts to cover the glaciers increases the melting, after the thickness exceeds 4-5 $\mathrm{cm}$, it provides a strong insulation. Moerover, as the thickness increases, the mass loss of the glacier under the debris cover decreases. For this reason, especially in the high mountainside where the physical separation was discrete, a quick development of the debris cover leads to the formation of such glaicers and provides protection by insulation although all the glacial ice were completely melted. Çinaçor glacier, which is located in the southern part of the water section in the Tatos (Dilek) Mountains near the Tatos Breach, is at the western part of the area. On the other hand, Çatakkaya debris covered glacier is located in the eastern part of the southern glaciation of the Tatos Mountains, inside a cirque surrounded by the high ridge and slopes at an elevation of approximately $3500 \mathrm{~m}$ (Figure 2, 3).

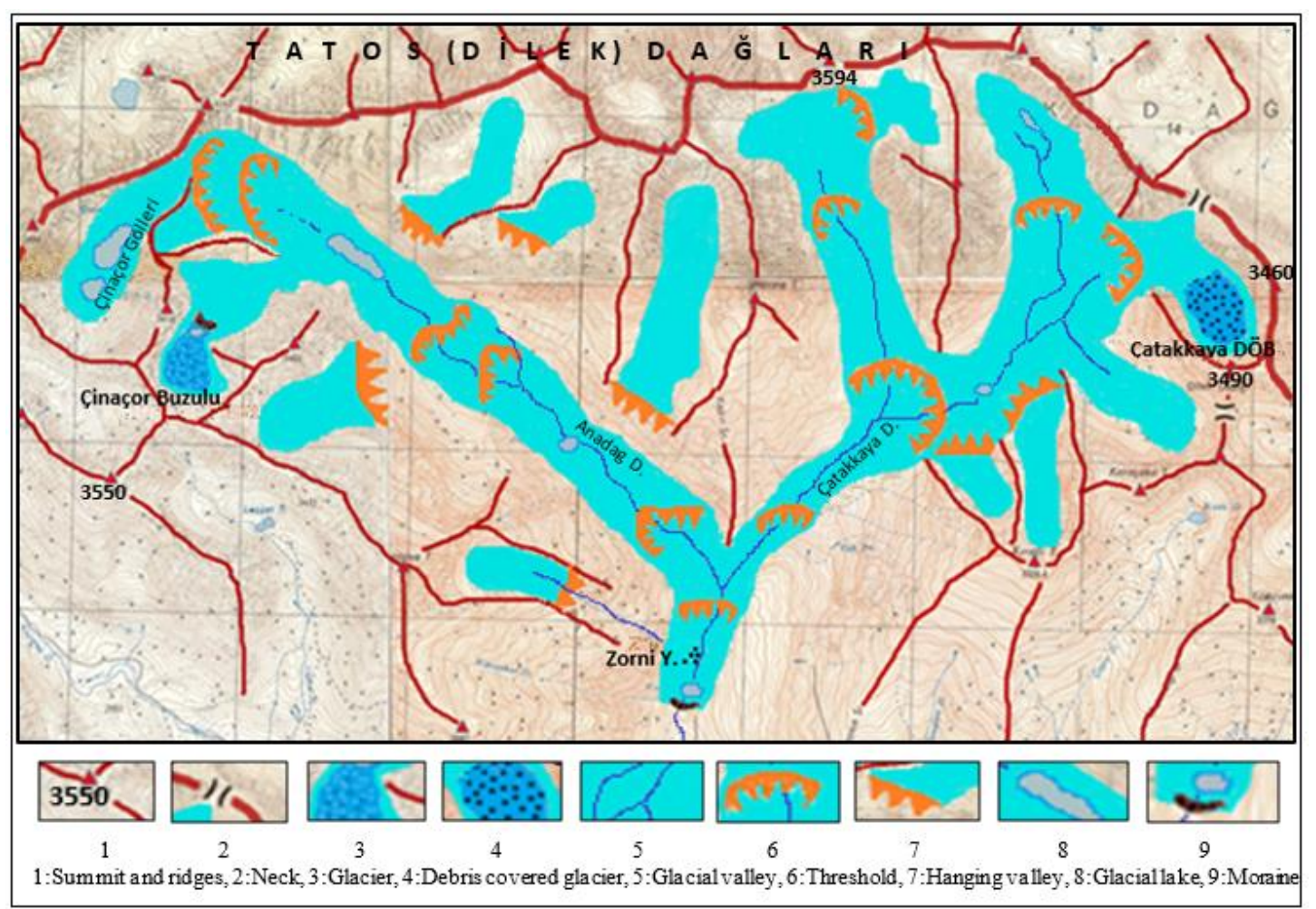

Figure 2. Glacier valleys on the southern slopes of the Tatos Mountain and the location of the Çatakkaya and Çinaçor glaciers. 
The glacial topography at the south of the water section consists of syncline valleys, hanging valleys and glacial lakes made by glaciers fed from many cirques. Nowadays, the glaciation in this area, which mainly contains two current glaciers among the north faced cirques, has formed two distinct syncline valleys. The length of the glacial valleys near the Zorni Plateau could reach up to 6 $\mathrm{km}$.

Total length and width of the Çatakkaya debris covered glacier, which is almost completely covered by a sheet of debris, are around $520 \mathrm{~m}$ and $400 \mathrm{~m}$, respectively. The waste material covering the glacier is composed of fine elements and also have smaller thickness at the upper sections of the cirque. As was gone through the lower sections, the volcanic elements forming the cover become larger and the visible thickness of this covering turning into large blocks exceeds 10 meters.

Three stages were determined in Çatakkaya debris covered glacier due to the morphology of the glacial mass under the debris cover (Photo 2). These levels are characteristic not only in terms of elevation and slope conditions, but also in terms of the dimensions of the material forming the cover and relative novel-ancient relationship. Some features of this type of glacier, almost all of which are covered with debris cover and therefore difficult to determine, also provide important clues on this issue. One of the most important of those is the presence of a lake on the debris material. There were detected 4 small lakes reflecting these conditions on Çatakkaya debris covered glacier (Photo 3). They are located at the least inclined part of the surface and between the sets formed by the debris material near the spit.

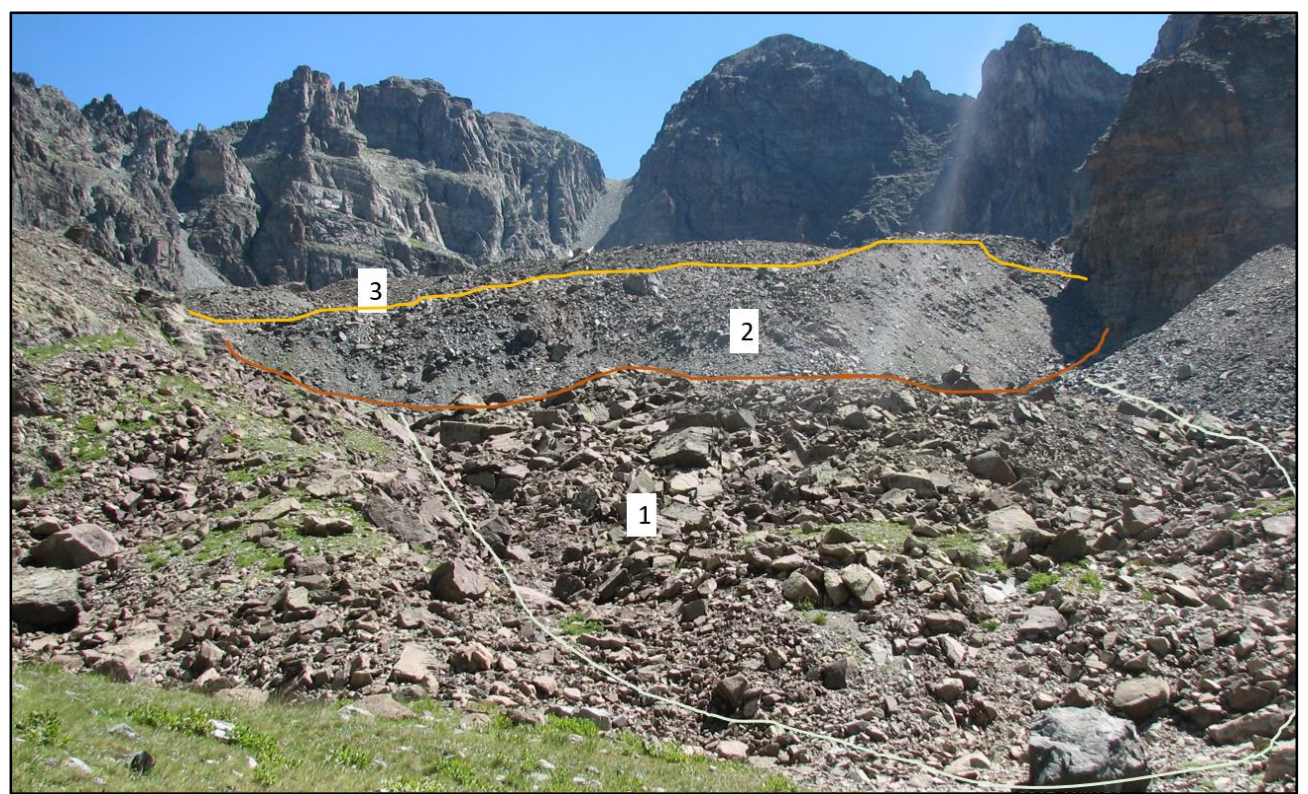

Photo 2. View from the lower part of the covered glacier of Çatakkaya. The three levels formed by the debris cover are clearly

The lake at the upper side occured in a sedimentation area, while the others occured in the depressions formed in the depressions within the debris bulk. Dimensions of the lake occured as a result of the subsidence was about $5 \times 8 \mathrm{~m}$ and the height of the visible section of the ice cliff 
surrounding one edge was about 80-100 cm (Photo 4). Çatakkaya debris covered glacier, including cirque slope is covered with a debris sheet.

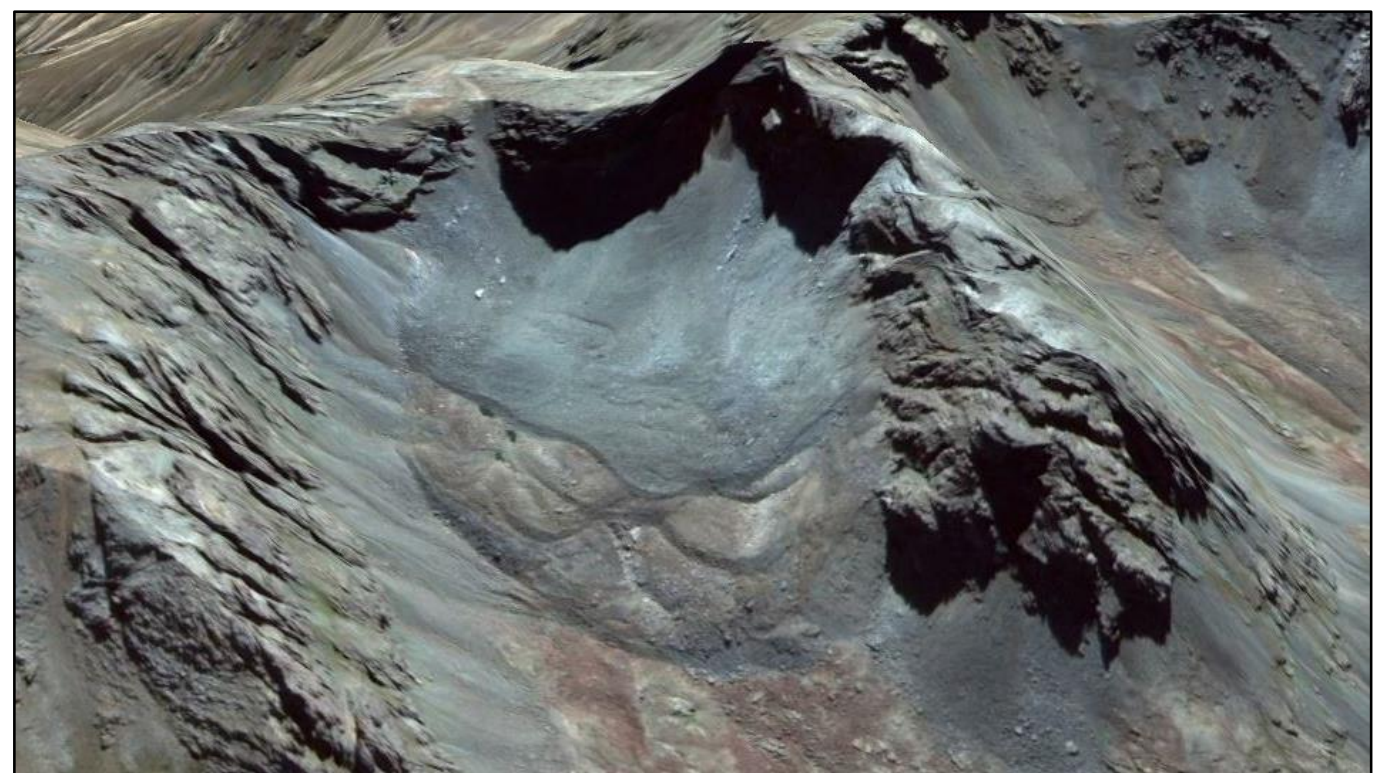

Photo 3. Google Earth image of Çatakkaya glacial covered glacier. Lobes reflecting the movements of the glacier in the debris cover and small glacial lakes give important clues for the determination of such glaciers. It is noteworthy that there is no water outlet due to melting in the lower part of the surface, on the surface or in the lower part.

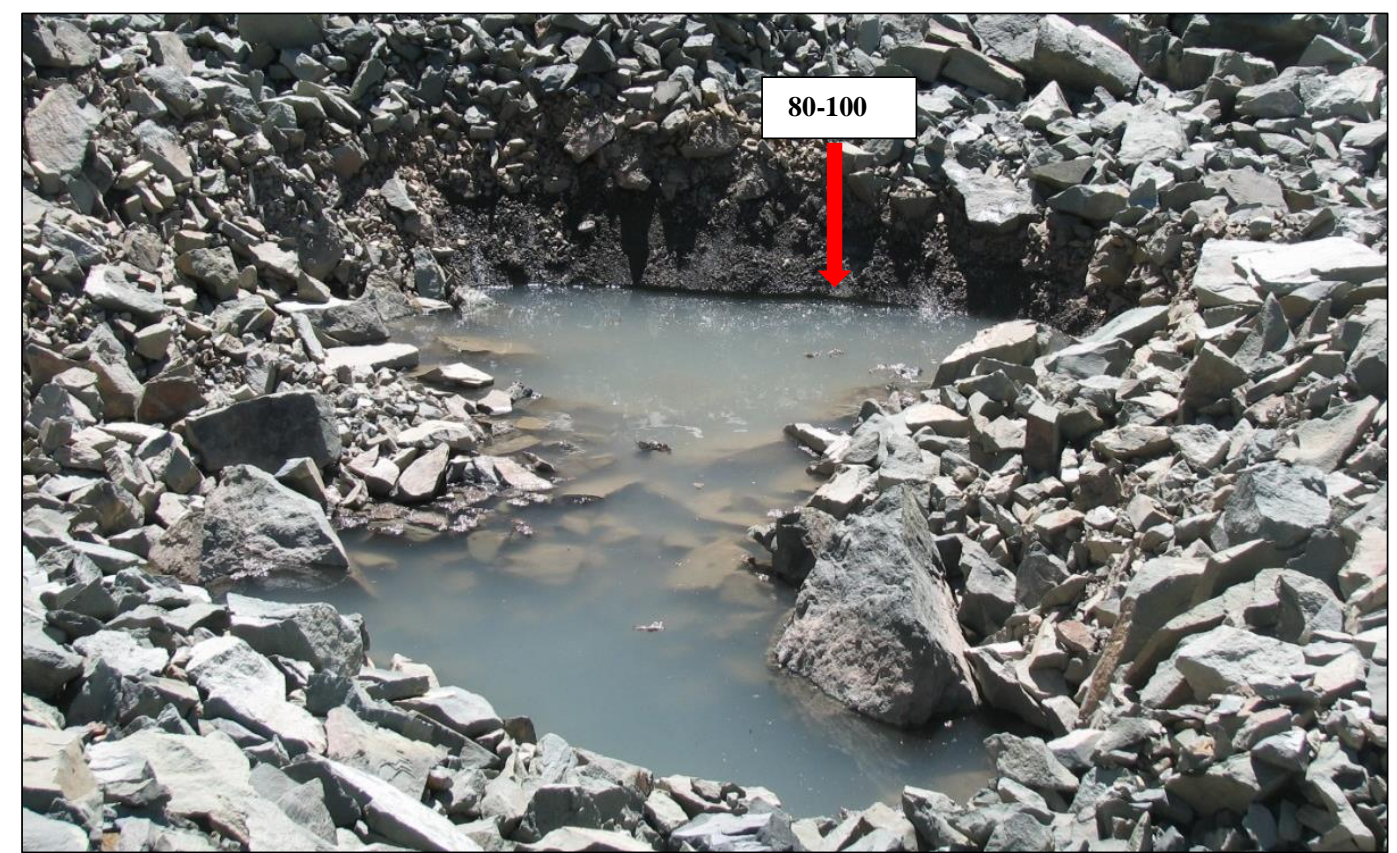

Photo 4. An ice cliff of $80-100 \mathrm{~cm}$ is surrounded by a small supraglacial lake on the Çatakkaya debris covered glacier. These small supraglacial lakes on the debris covered glacier are the places where ablation is the highest.

However, since the debris cover in this section is composed of thin and small size elements, small melting channels have been formed in some places, which are swept up due to glacial flow. Moreover, it is unlikely that these small surface parts that were revealed by the glacier can be seen 
remotely. Especially in the upper parts of the glacial area where the slope is high, the debris cover is very thin. That is why clean glacial ice emerges in some places when the surface cover is excavated 5$10 \mathrm{~cm}$, (Photo 5). It is difficult to reach the glacier at lower parts since the sheet thickness increases. The debris material that covers the lower part of the glacier shows a rock glacier form depending on the structure and shape of the ice mass below it. However, it is extremely difficult to understand that there is a glacier or ice core under this debris covering, without seeing the glacial surface.

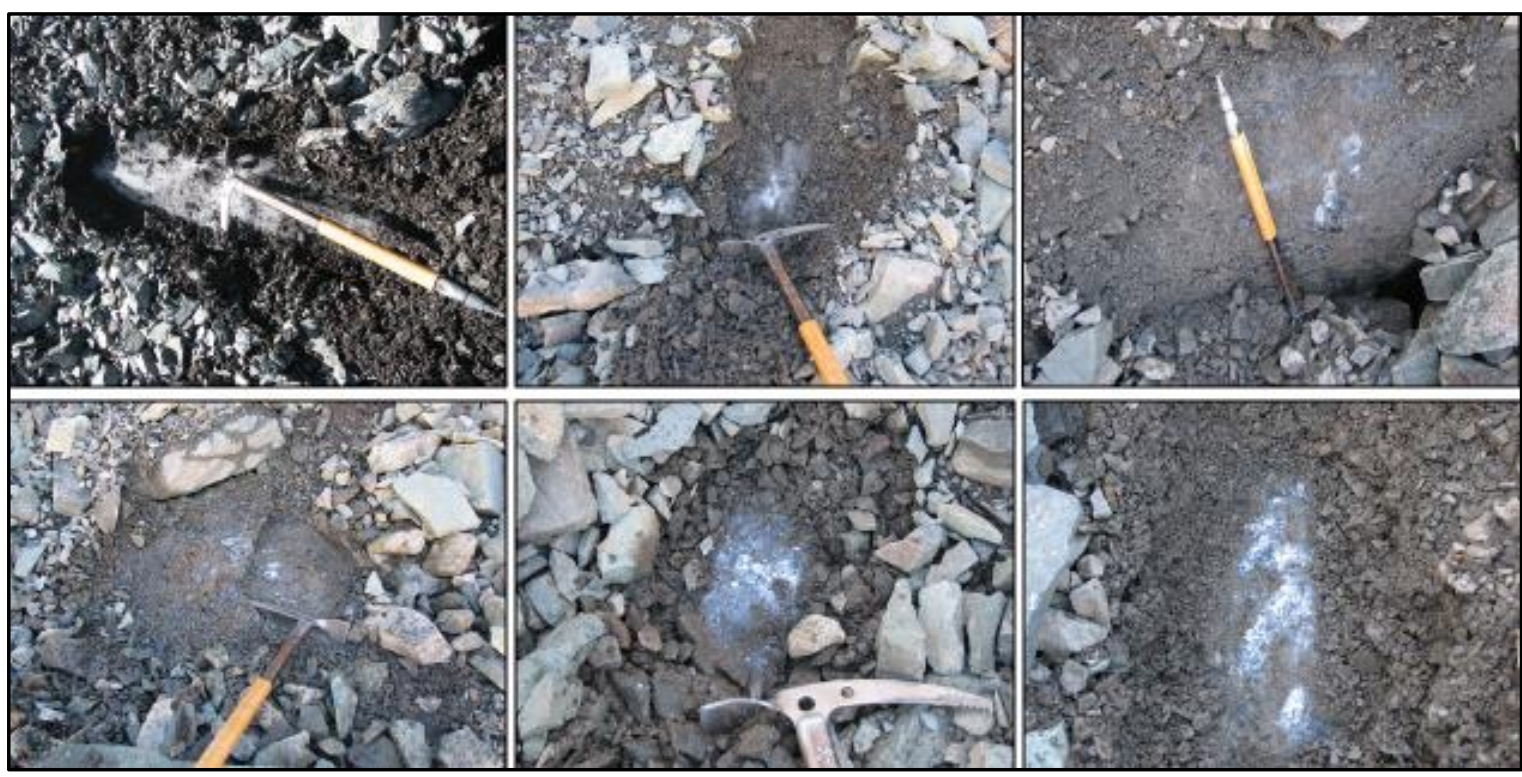

Photo 5. Because the entire surface of Çatakkaya glacier is covered with debris, the glacial ice surface is almost never seen.However, the glacier is exposed when the surface covering material is slightly mapped.The glacial ice surface, which is reached up to $5-10 \mathrm{~cm}$ in the upper parts, is much deeper due to the thickness of the cover as it goes down.

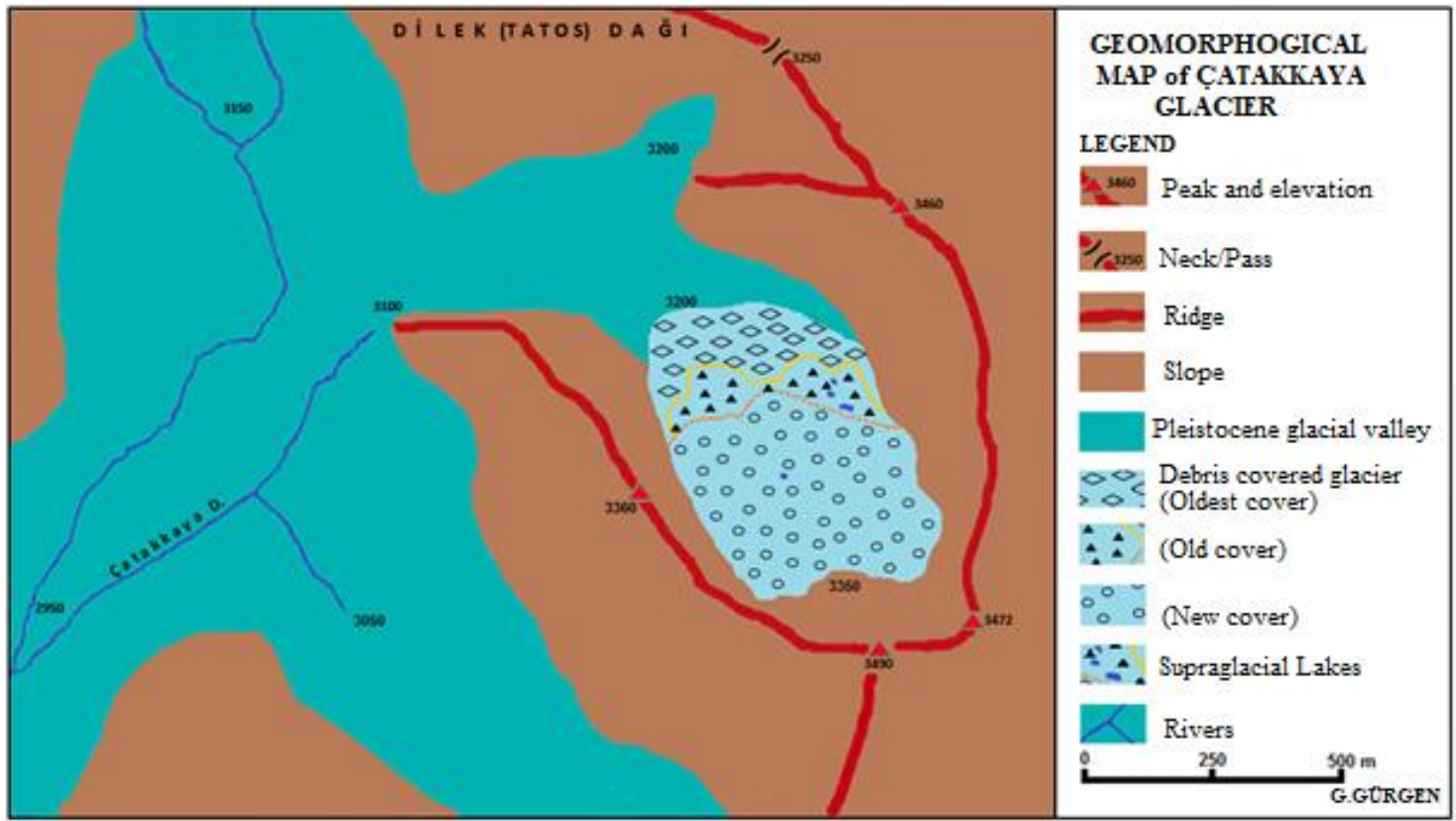

Figure 3. Geomorphological map of Çatakkaya debris covered glacier and its surroundings. 


\section{Conclusion}

Tatos (Dilek) Mountains have a magnificent glacial topography at the high parts of the southern slopes. Depending on the conditions of elevation and exposure in this area, some small current glaciers have survived to the present day. Tatos Mountains attract attention with its peaks exceeding 3500m and glacial lakes. Various studies in this area have reached important information about glacial topography and glacial conditions. For example, the current glaciers on the Eastern Black Sea Mountains have been included in these studies for the first time. However, some recent research has revealed the existence of some small current glaciers still unknown in the region. While these studies provide information on newly identified glaciers, it is also discussed why new findings could not be reached by this time.

Eastern Black Sea Mountains, is a major glaciation areas of Turkey. However, the present glacier presence is limited. In the southern part of the North Anatolian Mountains, where the current glacial presence is also extremely limited. Therefore, it is important to determine the location, characteristics and current situation of the current glaciers of the North Anatolian Mountains. For this reason, the Çatakkaya Debris covered glacier is an important finding in the eastern Black Sea Mountains, which is added to a few known glacial beings. Together with the glacier "Çinaçor" to the west of the Tatos Mountains, the presence of two separate glaciers on the southern slope of this region is determined for the first time. Due to changing climatic conditions and increasing temperature values, glaciers are in the phase of extinction. It is understood that clean glaciers, which are limited in this area (but their lower parts are covered with debris), are transformed into debris covered glaciers and ice core rock glaciers when appropriate conditions are formed. This phenomenon, depending on the climate and environmental conditions, indicates the situation that arose in the final stages of the glacial presence.

In recent years, the data obtained in the studies conducted in the North Anatolian Mountains reveal that new findings can be reached in the detailed researchs to be carried out from this perspective and that some new small glaciers can be determined before they are completely melt away.

\footnotetext{
Notes

1. Çatakkaya is the name of the village whose former name is Çinaçor. This village is connected to the town of Ispir in Erzurum.

2. A part of this article is presented as a paper at the International Congress on the 75th Anniversary of Turkish Geographical Society (Ankara-2017).
}

\section{Referanslar/References}

Akçar, N., Yavuz, V., Ivy-Ochs, S., Kubik, P.W., Vardar, M., Schluchter, C. (2007). Paleoglacial Records from Kavron Valley, NE Turkey: Field and Cosmogenic Exposure Dating Evidence. Quaternary International, 164-165, 170-183.

Akçar, N., Yavuz, V., Ivy-Ochs, S., Kubik, P.W., Vardar, M., Schluchter, C. (2008). A Case for a Downwasting Mountain 285.

Glacier During Termination I, Vercenik Valley, Northeastern Turkey. Journal of Quaternary Science, 23 (3), 273 -

Çiner, A. (2003). Türkiye’nin Güncel Buzulları ve Geç Kuvaterner Buzul Çökelleri, Türk. Jeo. Bül. 46 (1). 
Doğu, A.F., Somuncu, M., Çiçek, İ., Tunçel, H., Gürgen, G. (1993). Kaçkar Dağında Buzul Şekilleri, Yaylalar ve Turizm. A.Ü. Türkiye Coğrafyası Araştırma ve Uygulama Merkezi Dergisi, 2, 157-184.

Doğu, A. F., Çiçek, İ., Gürgen, G., Tunçel, H. (1996). Üçdoruk (Verçenik) Dağında Buzul Şekilleri, Yaylalar ve Turizm, A.Ü, Türkiye Coğrafyası Araştırma ve Uygulama Merkezi Dergisi,5,29-51.

Doğu, A.F., Çiçek, i., Gürgen, G., Tunçel, H. (1998). Bulut-Altıparmak Dağlarında Buzul Şekilleri, Yaylalar ve Turizm. A.Ü, Türkiye Coğrafyası Araştırma ve Uygulama Merkezi Dergisi, 6, 63-92.

Erinç, S. (1945). Doğu Karadeniz Dağlarında Glasyalmorfoloji Araştırmaları, İst. Üniversitesi Edebiyat Fakültesi Yay. Coğ. Ens. Dok. Tez. Ser. No: 1, İstanbul.

Erinç S. (1949). Kaçkardağı Grubunda Diluviyal ve Bugünkü Glasyasyon (Eiszeitliche und Gegenwartige Vergletsche-rung in der Kaçkardag-Gruppe), Ist. Üniersitesi Fen Fak. Mec. Seri. B.C. XIV, 3, 243-245.

Erinç, S. (1952). The Present Glaciation in Turkey, General Assembly and 17th International Congress of the International Geographical Union, 8th Proceedings, Washington.

Gall, H. (1966). Gletscherkundliche Beobachtungen im Hochgebirge von Lasistan (Nordostanatolisches Randgebirge). Mitteilungen der Osterreichischen Geographischen Gesellschaft, 108, Heft II/III.

Gürgen, G. (2001). Karadağ (Gümüşhane) Çevresinin Glasyal Morfolojisi ve Turizm Potansiyeli. A. ̈, Türkiye Coğrafyası Araştırma ve Uygulama Merkezi Dergisi, 8, 109-131.

Gürgen G. (2006). Üçdoruk-Dilek Dağları Güneyinin Glasyal Morfolojisi. Coğrafi Bilimler Dergisi, 4, (2), 65-79.

Gürgen, G., Çalışkan, O., Yılmaz, E., Yeşilyurt, S. (2010). Döküntü Örtülü Buzullar ve Kaya Buzulları (Debris-Covered Glaciers and Rock Glaciers). e-Journal of New World Sciences Academy, 5, (1), 32-45.

Gürgen, G., Yeşilyurt, S., (2012). Karçal Dağı Buzulları (Artvin), Coğrafi Bilimler Dergisi, 10, (1), 91-104.

Gürgen, G. 2014. Verçenik Dağı Buzulları (Rize Turkey). VIII Coğrafya Sempozyumu, 23-24 Ekim 2014, Bildiriler Kitabı içinde, 73-86, Ankara.

Gürgen, G. (2015). Tatos Gediği Buzulu (Rize)”, Coğrafi Bilimler Dergisi, 14, (1) 57-69.

Gürgen, G. (2016). Çinaçor Buzulu (Tatos Dağları) Coğrafi Bilimler Dergisi, 13, (2) 161-171.

Krenek, L. (1932). Gletscher im Pontischen Gebirge. (Lasistan), Zeitschrift f. Gletscherkunde. Bd. 20, 129-131, Bildtafel XV u. XVI.

Kurter, A. (1991). Glaciers of the Middle East and Africa-glaciers of Turkey. Richard,S., Williams, R. S., Ferrigno, J.G. (Ed), Satellite Image Atlas of Glaciers of the World. United States Geological Survey Professional Paper, 1386-G-1,1-30.

Leutelt, R. (1934). Im Hochgebirge von Lasistan, Osterr Alpenzeitung Wien, Falge 1145, 127 - 140.

Leutelt, R. (1935). Glazialgeologische Beobachtungen im Lasistanischen, Hochgebirge. z. f, Gletscherkde. 23 , S. 67 - 80.

Loffler, E. (1970). Untersuchungen zum Eiszeitlichen und Rezenten Klimagenetischen Formenschatz in den Gebirgen Nordostanatoliens: Heidelberg Geographische Arbeiten Heft: 27, Heidelberg.

Reber, R., Akçar, N., Yesilyurt, S., Yavuz, V., Tikhomirov, D., Kubik, P.W., Schlüchter, C. 2014. Glacier Advances in Northeastern Turkey Before and During the Global Last Glacial Maximum. Quaternary Science Reviews, 101, 177 192.

Sarıkaya, M.A., Çiner A, (2015). Türkiye Geç Pleyistosen Buzullaşması ve Paleoiklimi, MTA Dergisi, 151, 111-132.

Takeuchi, Y., Kayastha, B,R., Nakawo, M. (2000). Characteristics of Ablation and Heat Balance in Debris-free and DebrisCovered Areas on Khumbu Glacier, Nepal Himalayas, in the Pre-Monsoon Season. Debris-covered Glaciers. Nakao, M., Fountain, A., Raymond, C.,F. (Ed), Washington: IAHS Publication, No: 264, 53-61.

Tomphson, M.H., Kirkbride, M.P., Brock, B. W. (2000). Twentieth Century Surface Elevation Change of the Miage Glacier, Italian Alps. Debris-covered Glaciers. Nakao, M., Fountain, A. ve Raymond, C.,F., (Ed), Washington: IAHS Publication, 264, 219-225. 